Illinois State University

ISU ReD: Research and eData

Theses and Dissertations

$3-6-2021$

\title{
Gobelin or Guild?: A Foucauldian Analysis of Teachers' \\ Professional Learning Under the Illinois Essa
}

Carrie Hruby

Illinois State University, hrubycarrie@gmail.com

Follow this and additional works at: https://ir.library.illinoisstate.edu/etd

\section{Recommended Citation}

Hruby, Carrie, "Gobelin or Guild?: A Foucauldian Analysis of Teachers' Professional Learning Under the Illinois Essa" (2021). Theses and Dissertations. 1441.

https://ir.library.illinoisstate.edu/etd/1441

This Dissertation is brought to you for free and open access by ISU ReD: Research and eData. It has been accepted for inclusion in Theses and Dissertations by an authorized administrator of ISU ReD: Research and eData. For more information, please contact ISUReD@ilstu.edu. 


\section{GOBELIN OR GUILD?: A FOUCAULDIAN ANALYSIS OF TEACHERS' PROFESSIONAL LEARNING UNDER THE ILLINOIS ESSA}

\section{CARRIE E. HRUBY}

\section{Pages}

In this study I use Foucauldian theory to illuminate and analyze the use of surveillance, observation, hierarchical observation, normalizing judgment, and examination by federal and state governments' education departments in Illinois’ ESSA policy. I conduct a discourse analysis of the Illinois ESSA Plan, specifically use of the IL-EMPOWER Network for mandating failing schools' teachers' professional learning, using the Foucauldian concepts of surveillance, observation, normalizing judgment, and examination to reveal the control of the state. Understanding educators need professional development to serve all students well, I begin by offering an historical review of professional development and its evolution over time. I then lay a foundation for my analysis by defining and explaining Foucault's theories of surveillance, observation, normalizing judgment, and the examination, using this frame as the lens through which to analyze the IL ESSA. I submit findings of my analysis and offer conclusions and implications to public schools and public educators. Given this policy's meaning and value to educators, I finally pose questions about how school leaders and state-level policymakers might resolve or address those points I raise in my analysis.

KEYWORDS: IL ESSA; Foucault; teacher professional learning; factory model; collaboration 
CARRIE E. HRUBY

A Dissertation Submitted in Partial

Fulfillment of the Requirements

for the Degree of

DOCTOR OF EDUCATION

Department of Educational Administration and Foundations

ILLINOIS STATE UNIVERSITY 
(C) 2021 Carrie E. Hruby 
GOBELIN OR GUILD?: A FOUCAULDIAN ANALYSIS OF TEACHERS’ PROFESSIONAL

LEARNING UNDER THE ILLINOIS ESSA

CARRIE E. HRUBY

COMMITTEE MEMBERS:

Stacy Otto, Chair

Beth Hatt

Pamela Twyman Hoff 


\section{ACKNOWLEDGMENTS}

You may encounter many defeats, but you must not be defeated. In fact, it may be necessary to encounter the defeats, so you can know who you are, what you can rise from, how you can still come out of it.

- Maya Angelou

The journey to my Ed.D. was paved in persistence. Without the support of loved ones, colleagues, and mentors, I likely would have thrown in the towel.

I want to acknowledge my best friend and husband, Scott, for his support and confidence in me. You never gave up on me, even when I tried to give up on myself. You are the person I want by my side every day of this beautiful life.

To my wonderful and intelligent children—Will, Luke, Ben, Kate, and Claire-for their patience and for making me want to be a better mother and model. May you never stop learning but pause to enjoy the beauty of the world around you. Remember always that good enough isn't.

To my first and best teachers — my parents—-for their unconditional love and support. You taught me to love learning and to believe in myself.

I would like to thank Dr. Stacy Otto for never giving up on my pursuit of the dream to achieve my doctorate. You inspire me. I also express my gratitude to Drs. Hatt and Hoff for your guidance and wisdom.

To my colleagues and friends who have supported and encouraged me throughout my pursuit, I thank you for holding me accountable and cheering for me. 
Most importantly, I humbly acknowledge God for being the rock that tethers me to my priorities in life.

I hope I’ve made you all proud.

C.E.H. 


\section{CONTENTS}

Page

ACKNOWLEDGMENTS

CONTENTS

FIGURES

CHAPTER I: INTRODUCTION TO THE STUDY 1

Background of the Problem $\quad 1$

$\begin{array}{ll}\text { Statement of the Problem } & 5\end{array}$

Why Is Collaboration Not Enough? 12

$\begin{array}{ll}\text { Significance of the Study } & 14\end{array}$

$\begin{array}{ll}\text { Purpose of the Study } & 16\end{array}$

$\begin{array}{ll}\text { Methodology } & 17\end{array}$

$\begin{array}{ll}\text { Research Problem } & 19\end{array}$

CHAPTER II: REVIEW OF THE LITERATURE 24

Introduction: Content, Scope, and Organization of the Literature Review 24

$\begin{array}{ll}\text { The Evolution of Professional Development } & 24\end{array}$

Review of Research $\quad 32$

Gap Analysis 33

CHAPTER III: METHODOLOGY 40

$\begin{array}{ll}\text { Introduction } & 40\end{array}$

$\begin{array}{ll}\text { Research Method } & 41\end{array}$

$\begin{array}{ll}\text { Theoretical Framework } & 45\end{array}$

Surveillance and Observation $\quad 50$ 
$\begin{array}{ll}\text { Normalizing Judgment } & 54\end{array}$

The Examination $\quad 56$

$\begin{array}{ll}\text { Docile Bodies } & 56\end{array}$

$\begin{array}{ll}\text { Justification of Theoretical Frame } & 58\end{array}$

$\begin{array}{ll}\text { Social Reproduction Theory } & 60\end{array}$

$\begin{array}{ll}\text { Researcher Subjectivities and Biases } & 60\end{array}$

$\begin{array}{ll}\text { Research Limitations } & 61\end{array}$

CHAPTER IV: ANALYSIS OF DATA 63

Omnipresent Warder via a Microscope of Data 63

The Voice of the Marginalized $\quad 75$

Foucault’s Examination and the Inevitable “Good School/Bad School” Dichotomy 76

Omnipresent Oversight of State Agency Officials 86

The IL-EMPOWER Network as Gobelin $\quad 87$

Autonomy Must Be Bestowed upon You, Docile Bodies 94

$\begin{array}{lr}\text { Conclusion } & 95\end{array}$

$\begin{array}{ll}\text { CHAPTER V: FINDINGS AND RECOMMENDATIONS } & 97\end{array}$

$\begin{array}{ll}\text { Research Findings } & 97\end{array}$

The IL ESSA's Creation of a "Fair Contest” 99

$\begin{array}{ll}\text { Perpetuating School Failure } & 102\end{array}$

$\begin{array}{ll}\text { The Real Power of the IL ESSA } & 105\end{array}$

$\begin{array}{ll}\text { Recommendations } & 106\end{array}$

$\begin{array}{ll}\text { REFERENCES } & 114\end{array}$ 


\section{FIGURES}

Figure $\quad$ Page

1. Panopticon design schematic, Jeremy Bentham (1791) 51 


\section{CHAPTER I: INTRODUCTION TO THE STUDY}

\section{Background of the Problem}

Many thousands of dollars and hundreds of hours are spent by school districts every year on professional development for teachers and administrators in an attempt to create good schools out of bad schools; U.S. schools are perennially locked in a good school/bad school dichotomy. Billions are spent at the federal level (Calvert, 2016) and policies are drafted or reauthorized each year in an effort to improve failing and troubled schools. Throughout my career as an educational leader, I have had experiences that make me question the effectiveness of the use of many professional development resources and practices. For example, I have watched as educators unilaterally select workshops based on their own personal interest, a marketer’s pitch, or a new "silver bullet" fad. Some find ways to connect their selections to school or district goals in an attempt to ensure approval of funds by the central office. Others review a list of offerings from a Regional Office of Education and hope to find relevant information or workshop dates and convenient locations. Educators are often left to be curators of professional development, gathering bits and pieces of disconnected training as it fits into their schedules or sparks their interest. Educators experiencing the PD potpourri are left to make sense and use of a fragmented and arbitrary curriculum and often left voiceless and without agency in the selection of professional learning activities. Educators and researchers agree; traditional, à la carte, PK-12 professional development opportunities are ineffective (Calvert, 2016; Bill \& Melinda Gates Foundation, 2014; Desimone et al., 2002). Sparks (2004) argues numerous educators are still passively engaged in low-quality, mandatory workshops that offer nothing more than the opportunity to earn continuing education credits to be applied toward state recertification requirements. While these requirements may set the expectation for seat time, they are not 
enough (Calvert, 2016) and end up creating disengaged adult learners who are following rules or checking off a requirement. For, "Embarking on any path of personal growth is a matter of choice. No one can be forced to develop his or her personal mastery. It is guaranteed to backfire” (Senge, 1990, p. 172). Being required to check a box of professional development completion does not create agency and will not turn around a troubled or failing school.

Too often, schools do not resemble learning organizations because of the pressure to conform to state or federal policies, procedures, and rules on professional learning (O'Neil, 1995). An increase in accountability demands from federal legislation such as the No Child Left Behind Act (2001) and, subsequently, the Every Student Succeeds Act (ESSA) (2015), juxtaposed with a reduction of financial resources from state government, hamstring educational leaders required to meet higher professional learning standards with fewer means and less time. Ultimately, most professional development opportunities are episodic (DuFour, 2014), infrequent and intermittent, shallow, not valuable (DeMonte, 2013), and not specific to teacher needs, reflecting an industrial model created to meet pre-established requirements (Breneselovic \& Krnjaja, 2012).

Ever searching for a panacea to the dilemma of ineffective professional development activities, enter the popularity of professional learning communities (PLCs), which promised to provide the best conditions for staff learning and capacity-building (DuFour, 2014) as well as to be "the" solution to school improvement (DuFour \& Eaker, 1998). Proponents of the PLC model argue the collaborative and shared leadership design of PLCs positively affects student achievement data (DuFour \& Eaker, 1998). However, no matter the sound theory behind PLCs, a lack of experienced, thoughtful leaders available to implement any well-intentioned collaboration model decreases dramatically the PLC model's ability to move colleagues beyond 
staff learning focused on low-level interactions that do little more than maintain teachers' current instructional practices (Fallon \& Barnett, 2009b). In fact, Ricken (2011) finds the PLC model to have no effect on the two studied schools' achievement rates that implement it. Specifically, he finds both schools' teachers embraced the PLC model with eagerness and enthusiasm to improve student achievement. Still, they disappointingly were unable to do so after many book studies, collaboration sessions, and curriculum planning committees (Ricken, 2011). The time spent did not improve student achievement scores (Ricken, 2011). While time spent is not wasted since educators need outlets to converse and discuss strategies and best practices, much of what is considered collaboration instead conserves the use of current practices and does not lead to improved student achievement (Little, 1990). If a school’s focus turns away from student outcomes, the time and energy spent in meetings and workshops will not affect achievement (Ricken, 2011). Many workshops focus on teacher stories, but when teachers are left to their own devices to share stories, a low-level brand of collaboration fills the void where thoughtful, creative, challenging professional development and learning should be (Little, 1990). Although sharing allows teachers the opportunity to support one another, it does not result in systematic improvement. If the experiences they share are not in line with research-based approaches or are merely a way to check off a list of certification requirements, then teachers risk spending valuable professional development time and precious fiscal resources offering one another lessthan-effective strategies (Little, 1990). Underlying my study is the argument PLCs that embrace fragmented, low-level collaborative professional learning activities serve merely to perpetuate teachers' current instructional practices and check the seat-time box, rather than inspiring and educating teachers in a collaborative setting to embrace new, research-based instructional practices informed by teacher expertise and encouraging teacher agency. 
A more recent shift in professional development and collaboration was introduced by the Every Student Succeeds Act (ESSA) (2015), which amends Section 8302 of the federal Elementary and Secondary Education Act of 1965 (2015). ESSA was signed into law in December 2015, with bipartisan support and tasks each state to articulate its plan to ensure students are career- and college-ready. The Illinois State Board of Education drafted Illinois' ESSA plan following input from stakeholder groups in April 2017. The U.S. DOE later approved Illinois’ ESSA on August 30, 2017.

Written by Illinois State Board of Education (ISBE) officials, the Illinois ESSA plan (ISBE, 2017) is ISBE's policy response to federal requirements. The policy attempts to address professional learning and collaboration limitations with its IL-EMPOWER Network. The IL ESSA plan provides a 15-year timeline for Illinois to meet academic goals to align with the federal ESSA. It requires schools that do not meet statewide benchmarks to engage in professional collaboration and training with an approved partner from its IL-EMPOWER Network, whose partners are drawn largely from "successful” schools in white, middle-class suburban areas. The Network functions as the state-approved professional development and mentoring delivery mechanism for schools not meeting predefined targets for professional learning: those schools labeled "failing."

The ISBE website defines the Network as "a statewide system of differentiated supports and accountability to improve student learning, purposely designed for capacity development to leverage schools’ strengths to meet student needs” (ISBE, 2019). The IL-EMPOWER Network replaces the state's previous one-source model that required schools to use consulting services from one vendor who bid on and received a contract with the state for professional development. This point is significant to my argument because while the state requires schools to use the multi- 
vendor Network, the policy language leads school leaders inaccurately to presume they have a choice in professional development via a list of approved partners, however the state holds the power. In addition, the documents used by the state to publicize the IL-EMPOWER Network and promote schools' use of the Network reflect a discourse more aligned with what research says educators need for professional development to be effective such as the need for jobembedded, timely learning guided by the needs of each educator (Bill \& Melinda Gates Foundation, 2014; Darling-Hammond \& McLaughlin, 2016; Sparks, 2004). The ESSA document only seems to allow districts and schools to make decisions about professional development.

\section{Statement of the Problem}

Critical analysis allows for the revelation of inequities of power and consequences in policies such as IL ESSA. A critical, textual analysis of the IL ESSA policy is imperative because schools required to use its IL-EMPOWER Network are those labeled as underperforming and failing. I argue that while the ESSA authors may have intended to offer support to underperforming schools, the ESSA is steeped in discursive language, which sends the message that underperforming school personnel—-teachers and leaders—are unable to govern their own learning and growth, leading to the deprofessionalization of teachers and school leaders. The ESSA employs discursive language that underestimates educators' decision-making and illustrates how the state holds the power. The policy allows the state to divert decisionmaking from those most able to decipher a school's professional learning needs. While district leaders and teachers recognize the need for professional development (Poole, 2000; Rhodes \& Beneicke, 2002), the two groups must be provided an opportunity to work collaboratively to determine parameters and expectations for professional development goals, plans, and outcomes. 
Although strong educational leaders can influence teachers to embrace best practices, change is more likely to be sustained if policies guide professional learning programs (American Federation of Teachers et al., 2010). In a review of collective bargaining language, the American Federation of Teachers (AFT) (AFT et al., 2010) points to characteristics that signal a commitment to high-quality professional development. Included are results-based motivations, relevancy, understanding of diverse student learning styles, collaboration, clear vision for learning, reliance on teacher leadership in the design and facilitation of activities, and administrators’ commitment to learning more about quality professional development models (AFT et al., 2010). On the surface, the IL-EMPOWER Network represents an attempt to incorporate the AFT's valued characteristics, but in the ESSA the value of collaboration is underemphasized, and the ESSA does little to herald teacher leadership or teacher input on professional development design. It is instead riddled with exercises of power using an industrial model in which teachers are expected unquestioningly to accept the state's wisdom and values (Breneselovic \& Krnjaja, 2012). This relationship, however, proves problematic because effective professional development relies on both collaboration and teacher input (Little, 1990). Rather than controlling content that reflects a factory model, effective professional development is built on a systemic model that is collaborative, based on a network of relationships (Breneselovic \& Krnjaja, 2012).

The IL-EMPOWER Network represents a statewide attempt to improve professional development offered to Illinois educators. Although many districts have significantly changed the ways they approach adult learning and professional collaboration in light of research conducted throughout past decades, numerous teachers still passively are engaged in low-quality, mandatory workshops that offer nothing more than an opportunity to earn continuing education 
credits to be applied to state recertification and licensure requirements (Bill \& Melinda Gates Foundation, 2014; Sparks, 2004). This style of professional development devalues teachers’ knowledge and experience and sends a message that an external consultant knows more about their students' and the school community's needs than what teachers bring to the table after having worked with children, families, and in school communities on a daily basis (Lieberman, 1995).

While the quality of professional development varies, every year public school districts spend thousands of dollars and significant amounts of required time on professional development activities for administrators and teachers (Calvert, 2016). Education Resource Strategies finds Philadelphia spent nearly \$162 million on professional development in 2007-2008, including offering increased salary for college coursework, professional development initiatives, and contracted professional development days. In 2009, the U.S. DOE accounted for $40 \%$ of the three billion in annual Title II funds directed towards professional development (Calvert, 2016; Jaquith et al., 2010).

From state to state and district to district, funding for professional development varies greatly (AFT et al., 2010) because infrastructure and resources must be in place to meet the needs of educators. At the local level, funding can be used for professional development activities and at the state or regional level for technical assistance or statewide initiatives. State oversight can offer coherence and accountability (Jaquith et al., 2010), but at the risk of wounding educators’ confidence and impeding control of learning.

I find it encouraging that many educators agree passive, unengaging professional development is of low quality and does not improve instruction; therefore it essentially becomes a meaningless practice that merely fills a compliance requirement (Calvert, 2016). Low-level 
professional development, where educators are held hostage to a PowerPoint presentation (Bill \& Melinda Gates Foundation, 2014), is all too often the unfortunate result of leaders' attempts to address varied needs in short blocks of time with limited resources. While professionaldevelopment-focused policies attempt to improve this problem (Darling-Hammond \& McLaughlin, 2016), such policies require educators to register completed activities, but fall short of guaranteeing a cerebral, deep, critical, or meaningful implementation of professional learning and instead create disengaged educators (Bill \& Melinda Gates Foundation, 2014; Breneselovic \& Krnjaja, 2012).

Adult learners hope for a trusting relationship with a professional development partner (Rhodes \& Beneicke, 2002), the opportunity to make decisions about professional development, and learning practices that utilize problem-solving and hands-on experiences (DeMonte, 2013; Knowles, 1973). Adult professional development participants, particularly educators, want to understand the ways learning connects to their world and want to be able to apply information immediately in a way they see as meaningful. Adult learners, in particular teachers, want to play a significant role in the selection of PD topics and to know why and how the new knowledge is essential and how it applies to their background schema. They expect to have the opportunity to collaborate with peers and count on feedback as a follow-up (Archibald, 2011; DeMonte, 2013). Additionally, an effective professional learning environment is supportive and non-threatening (Knowles, 1973).

Flexibility in activity design is essential because adult learners, like students, learn in different ways. The most effective approach would be to include various learning opportunities, including but not limited to workshops, peer coaching, collaboration, book studies, mentoring, and action research (AFT et al., 2010; Penuel et al., 2007). Offering choice in the process of 
meeting individual learning goals helps teachers find flexibility and become more engaged (Lieberman, 1995). Teacher agency results from providing educators the opportunity to direct their own professional learning instead of professional development activities directed at or assigned to them (Calvert, 2016).

This type of flexibility can be offered without sacrificing high expectations by requiring teachers to develop and adhere to individual professional development plans via professional learning systems that support collaboration, choice, shared responsibility, and teacher involvement in data analysis (Calvert, 2016). District and school goals should drive learning plans and meet individual teachers' needs for continuous growth. While these plans can offer individual flexibility, educational leaders should be cautious that their implementation does not cause fragmentation or abandonment of collaboration (AFT et al., 2010).

To be sustainable, professional development must also be systemic and focused (Breneselovic \& Krnjaja, 2012). A fragmented approach that offers multiple, diverse innovations can leave teachers feeling overloaded, disjointed (Fullan, 1991), and uncertain of how to implement what they have experienced. As a result, shared decision-making results in far more robust PD programs (Jaquith et al., 2010) since "policies and collective bargaining language that allow for and respect teachers' involvement in decisions related to professional development increase the alignment among teachers' learning needs and those of their students” (AFT et al., 2010, p. 53).

Based on such research findings, and in a paradigm shift, high-performing districts have historically moved away from workshops delivered to large groups without regard to individual needs toward a system of job-embedded professional collaboration (Penuel et al., 2007). Small groups of educators learn from and with each other and master content through continuous 
dialogue based on authentic and timely issues. Collaboration is teacher-to-teacher and teacher-toadministrator, but positions are secondary to the conversation (Danielson \& McGreal, 2000). No longer do educators view professional development as something they "go to" or something that is "done to" them. Instead, they become actively involved in a culture of collaborative learning based on individuals' needs and linked to specific outcomes. The result is transformational professional learning that alters teachers' behavior, beliefs, and motivations (Danielson \& McGreal, 2000). This idealistic, theoretical perspective becomes the penultimate goal of professional development. However, the shift from top-down professional development offerings to newfound popularity for collaboration, specifically PLCs, perhaps inadvertently removes the expert from the learning. Instead, the PLC model relies on teachers to teach one another, problematic because professional development activities which engage collaboration between like-minded peers who are likely to have the same level of expertise on a given topic may provide neither challenge nor opportunity to learn. According to Vygotsky (1978), the zone of proximal development (ZPD), the distance between what a learner cannot do and can do unaided, requires appropriate assistance or guidance. Ideal learning in the ZPD may only be achieved when one group member has more experience or research knowledge (Vygotsky, 1978).

One group of researchers (Jaquith, Mindich, Wei, \& Darling-Hammond, 2010) studied four U.S. states—Colorado, Missouri, New Jersey, and Vermont—and suggest policy writers include best practices in state policies on professional learning. Specifically, policies should include a common vision for professional development, substantial monitoring of the quality, mentoring, induction considerations; a comprehensive system of supportive organizations; and permanence of funding and resources (Jaquith et al., 2010). The researchers establish 
...state policies and systems that ensure accountability and monitor professional development, when coupled with intermediary organizations that help extend the reach of state agencies, support professional learning, and provide a voice for local stakeholders and outside experts are necessary to improving student learning outcomes. (p. 4) The need for outside experts provides the opportunity for new challenges (Vygotsky, 1978). Policies that follow best practices will include language that addresses the need for resources and extended time for professional development in addition to an outside expert. Policy writers should also craft language to consider certificate renewal requirements, teacher collaboration, mentoring and induction, teacher compensation for involvement in professional development, flexibility in activity design, teacher leadership, and individual teacher plans for learning (AFT et al., 2010).

Educators' use of professional development time to share stories of little relevance or depth makes little impact on student learning. While advocates of collaboration point out its benefits, the level at which the collaboration is used should be differentiated to be effective (Little, 1990). Little identifies various levels of collaboration. The lowest of the levels offer settings in which teachers act independently but share ideas and reassurances in an effort either to reinforce current practices or create opportunities for themselves. Low-level collaboration activities consist of exchanges of stories or idea-sharing. More engaging, interdependent forms of collaboration emerge when teachers work with one another (Little, 1990). Aid-and-assistance collegial practices offer mutual aid, but teachers are cautioned not to advise or interfere, but only to offer support when asked. As a result, colleagues interact to confirm their current practice, not to evaluate one another. In the sharing level of collegiality, teachers openly exchange methods and ideas. In the strongest form of collegiality, joint work, participants actively reflect and 
collaborate to learn. I hypothesize joint work is possible when an expert is an active member of the collaboration.

\section{Why Is Collaboration Not Enough?}

Low levels of collaboration are non-confrontational, do not challenge the status quo, do not critically challenge teachers’ practices or philosophies, and do not involve risk-taking; instead, such activities offer what is often seen by teachers as a more-comfortable level of collaboration (Little, 1990). Yet professional learning becomes inadequate and limiting to educators when policies or leaders employ low levels of collaboration. Disappointingly, these low-level collaboration activities are often those most present in schools and the most likely to be reinforced by school leaders (Little, 1990). They denote collaborative activities in which information is distributed subjectively, support is offered only when requested, and information is assembled based on practices already in place. As a result, such forms of collaboration prove shallow and insubstantial in practice and seldom lead to noteworthy advancements or changes in teachers' routines or pedagogy, and therefore serve only to maintain the status quo (Fallon \& Barnett, 2009b). Educators do not challenge their pedagogy or underlying beliefs. Such forms offer no capacity or tools to build teachers’ and leaders’ critical consciousness, so deficit thinking, such as blaming students for their own educational failures, persists and grows (Valencia, 2010). The consequences of teachers' deficit thinking are students who fall victim to blame for the educational system's failures, which, in turn, negatively affects student outcomes: an endless, failing feedback loop. Shame and blame perpetuate negativity and do nothing to improve learning, outcomes, or school climate (Fallon \& Barnett, 2009a).

Little (1990) posits these forms of low-level collaboration perpetuate or reinforce mediocre or substandard performance. Put simply, low levels of collaboration lull staff members 
into a false complacency. Low levels of collaboration strengthen current practices and cultivate the status quo, lifting the status quo up as an example and offering excuses for not trying novel strategies by glorifying practices (Little, 1990) that do not challenge students and do nothing to narrow the opportunity gap (Ricken, 2011; Steen \& Noguera, 2010). Low levels of collaboration offer validation and compassion. While this can be comforting to an educator, sameness perpetuates current practices and becomes a barrier to improvement and new learning by those involved. Low levels of collaboration also deter educators from engaging in more powerful collaboration aimed at improving practices because teachers waste valuable, limited time in lowlevel collaboration activities (Fallon \& Barnett, 2009b). The IL-EMPOWER Network mandates a collaboration style of professional development with like-minded peers led by an approved outside expert. On the surface, the policy, therefore, meets educators' needs.

Meaningful, jointly conceived professional collaboration activities include mentoring, team teaching, co-planning, action research, and peer observation and coaching. These types of collegial activities are cohesive, promoting shared responsibility for student learning throughout the organization and allowing for more reflective dialogue and inquiry, leading to more effective instructional practices and improved learning. This is the most likely form of collegial work to create considerable improvement (Little, 1990), as teachers observe one another, offer critical reviews, and discuss practices. When teachers engage in joint work, the most effective type of PLC collaboration, they do not marginalize or buffer criticism of failed attempts. They show respect and trust for one another in the collaboration (Little, 1990).

Educators generally disapprove of professional development that is generic, single pointin-time, infrequent, and disconnected from teaching practices (DeMonte, 2013). Over time, such disdain in professional development activities resulted in a campaign for change by educational 
leaders who suggest traditional workshops lack the continuity and application needed to prepare teachers to meet all students' needs (McAdamis, 2007). A shift in the focus of the presenter serving as purveyor of knowledge to serving as the catalyst of adult learning therefore begins to change the landscape of professional development (DeMonte, 2013). Still, the number of teachers regularly involved in high-quality professional development varies widely (Jaquith et al., 2010. Policies such as the IL ESSA thereby have the potential to mend this disconnect if written and enacted appropriately.

\section{Significance of the Study}

In my 25 years as a teacher, assistant superintendent of curriculum, and now a district superintendent, I have personally witnessed the professional learning struggle. As budgets decrease and educational leaders realize the system is ineffective, many educators search for inexpensive ways to make learning more meaningful based on adult learners’ personal experiences. Knowing there is more personal "satisfaction” among teachers when a choice is available (Bill \& Melinda Gates Foundation, 2014; Lieberman, 1995), many leaders opt to offer educators the opportunity to collaborate in PLCs (DuFour \& Fullan, 2013), presuming that giving teachers license to lead their own professional development activities will lead to improved outcomes. However, in many of these sessions, I have witnessed low-level discussions about current practices or low-level conversations about sharing resources and lesson plans. In an attempt to allow educators choice in their learning, leaders set up regular collaboration activities for staff and provide time to share ideas and discuss challenges, however I often see this time used for staff to share stories or discuss lesson plans. It is dangerous and incorrect for educational leaders or teachers to assume these low-level conversations and sharing of resources will generate significant improvement in student achievement. 
There is a paucity of research on the way in which educational policies such as IL ESSA address issues of oppression. There is a distinct difference between professional learning that addresses teaching strategies and professional learning that addresses diversity, equity, and inclusion. Given a large percentage of U.S. public school teachers (and even more school leaders) are white, middle-class women (Shedrow, 2017), when given choices of professional learning, the vast majority of U.S. educators are not likely to self-select topics that take them out of their comfort zone. When they are unwilling to address topics of injustice and inclusion, there is a weakness in the system that is never addressed. But any dominating group, one example being white, middle-class educators, is not interested in relinquishing its place, maintains its position through laws and policies, and dehumanizes based upon race (Wilkerson, 2020). The lighter one’s skin, the more access to privilege one has, so darker skin is recast as subhuman. Coates (2015) theorizes, “The power of domination and exclusion is central to the belief in being white, and without it, 'white people’ would cease to exist for want of reasons” (p. 42). Established systems of oppression are difficult to address among people who see and want to challenge them, but these tasks become especially difficult with white, middle-class teachers who are uncomfortable discussing, or worse, unwilling to address or out-and-out defiant about addressing due to their privileged, colorblind social positioning.

Therefore, the text and practices of large-scale public school policies such as the IL ESSA end up reinforcing structures of domination statewide, when more thoughtful policy aimed at diversity, equity, and inclusion would legislate and guide this work among the largely white, middle-class teaching force. White teachers have been socialized into a white supremacist, colorblind, and deficit-thinking-focused society, and because of this they are going to use a universal approach to talk about longstanding issues of race and culture. These underlying, 
dominating belief systems afforded white teachers by their privileged background will need to be broken down and interrupted with professional learning that allows educators drastically to reframe their thinking (McKenzie \& Scheurich, 2004). Policies such as the IL-ESSA that do not recognize and meaningfully, thoughtfully address this critical need only reinforce structures of domination and oppression, passing these forms of negative socialization on to their young charges.

\section{Purpose of the Study}

The Illinois ESSA plan authors pledge to improve educators’ professional development and offer support and accountability to schools through the IL-EMPOWER Network as a means of professional development. I argue the type of support purported by the ESSA and the accountability required conflict with one another in the ESSA policy's discourse. In this study, I conducted a policy analysis, hypothesizing and exploring how the IL ESSA's policy language is crafted to require educators to believe they are incapable of leading professional development and must rely on the state to dictate, through legislation, which direction they must take to address struggling and failing schools. Through this textual policy analysis, I reveal how the IL ESSA uses discursive practices to attribute responsibility and authority to the agency by exploring professional development and student outcomes. I assert the ESSA discourse intimidates school personnel, as they are monitored and micromanaged by the state's education agencies. In a review of flaws in the nation's approach to the improvement of teaching, Hargreaves and Fullan (2012) proclaim:

In the face of solutions that haven’t worked, some people's answer is simply to push these solutions harder. Perhaps we just need better measurement, they say. Hundreds of millions of dollars are being poured into developing measurement systems that might be 
helpful for some purposes, but that will never drive up standards of quality in teaching. (p. 19)

I therefore investigate the ways the IL ESSA perpetuates the power of the state through hierarchical observation, normalizing judgment, and the examination, while purporting to offer what research says educators need for professional development to be effective, including the ownership of their learning (Bill \& Melinda Gates Foundation, 2014).

\section{Methodology}

A logical method used to analyze this policy and supporting documents is critical discourse analysis (CDA). CDA examines written and spoken language through a socio-political lens of communication (van Dijk, 1995). The methodology of critical discourse analysis is designed to make the power dynamics beneath and behind texts rise to the surface for critical analytical consideration with the intent of revealing inequities so social change can be embarked upon (van Dijk, 1993). CDA provides a critical approach to studying the text or talk and is problem or issue-oriented, often politically or culturally situated. This methodology focuses on group dynamics and how these dynamics are surrendered, counterattacked, or repeated. CDA analyzes all aspects of the discourse in a policy such as the IL ESSA. It is not only used to study word choice, grammar and syntax but also theme, organization, and style. Because discourse reflects the social and political tones of its environment, it often includes a sociopolitical perspective and openly exposes the political (van Dijk, 1995). CDA is used to analyze the ways in which discourse functions within social settings (Gee, 2011).

CDA work is often concentrated on elite power groups and illuminates the power that groups conceive, even when the power is obscure, underscored, or intentionally hidden (van Dijk, 1995). "That is, CDA specifically focuses on the strategies of manipulation, legitimation, 
and the manufacture of consent and other discursive ways to influence the minds (and indirectly the actions) of people in the interest of the powerful” (van Dijk, 1995, p. 18). This perhaps unintentional manipulation or influence of minds is my interest in this study. Through a CDA, I can evidence how the IL ESSA constrains educators' professional growth due to the inconsistencies between the widely accepted need for educators to guide their own learning and the discourse in the policy that places power and control in the hands of the state. I anticipate my research might inform those in a position to make revisions to the policy or future policies drafted guiding educator professional development. Therefore CDA is an appropriate method to analyze the IL ESSA policy and its supporting documents.

Analyzing the IL ESSA's language using a theoretical lens comprised of Foucault's (1995) theoretical concepts allows me to provide a deep exposition of the policy's unintentional subjugation. As a critical historian and archaeologist, Foucault views discourse as "a group of statements which provide a language for talking about—a way of representing the knowledge about—a particular topic at a particular historical moment” (Hall, 1992, p. 291). In this way, Foucault theorizes a specific truth and meaning emerges from its historical perspective (Hall et al., 2013). However, discourse is not limited to linguistics; rather, it is the combination of what is said and what is done or practiced as a culture of representation. Foucault was interested in the ways in which knowledge was produced through language (Hall et al., 2013). Employing a frame built from Foucauldian theory, I analyzed the text of the Illinois State Board of Education's Consolidated State Plan under the Every Student Succeeds Act in order to reveal ways in which the state establishes power over professional learning and to evidence the ways the state's power systematically is used to punish districts via observation, surveillance, and normalizing judgment. An analysis of policy language is appropriate because language is not passive; it 
constructs the world as a form of social action (Burr, 2015). In addition, Foucault's theorization of the design and role of social institutions such as schools provides a compelling frame through which to analyze the IL ESSA plan since the plan is a means of normalizing judgment meant ultimately to surveil and control Illinois’ educators.

In the course of my study I analyzed instances of the policy's various exercises of control, including the methods by which the IL-EMPOWER Network providers observe and report on educators' progress and create docile bodies. According to Foucault (1995), control and observation disperse power over groups to regulate and control individual behavior. Specifically, as a consequence of the policy's discourse, educators have less control over their own learning, which research and anecdotal evidence shows as necessary to meaningful professional development (Bill \& Melinda Gates Foundation, 2014), so are therefore disengaged. My analysis reveals and evidences how the social action that evolves from such control is detrimental to the policy’s intent. Gratefully, where there is control, there is resistance. Consequently, I argue educators governed by a policy such as the IL ESSA may be apt to resist this policy’s controlling purpose.

\section{Research Problem}

While PLCs became wildly popular as a foundation for trusting educators to share stories in collaborative settings, my analysis reveals how the IL ESSA exposes a lack of trust by the state that educators are inclined to or capable of "figuring it out" and "making it work" in order to turn around troubled and failing schools. The IL ESSA subjugates teachers’ expertise and agency by overseeing their learning opportunities and forcing compliance while representing the state’s goal as encouraging peer-to-peer professional learning. The IL ESSA also vanquishes 
educational leaders by divesting their influence in the development of professional learning activities and opportunities.

Although all policies limit choice and force compliance, the IL ESSA is particularly alarming due to its confining, anti-pedagogical approach. Researchers find educators must have the ability to choose professional learning topics for effective learning to occur (Bill \& Melinda Gates Foundation, 2014). Studies also suggest that peer collaboration leads to improved performance by educators, especially when coupled with self-analysis (Rhodes \& Beneicke, 2002). However, the IL ESSA removes choice and requires a partnership from a contracted vendor within the approved Network. This parameter confines and restricts teacher voices in professional development and creates an environment of professional disengagement and docility.

I hypothesized that this quandary unintentionally sets teachers and administrators up to fail students of color, immigrant students, low-income students, LBGTQ+ students, and students with disabilities who have individual needs but are subject to a policy intended to mass-produce guidance and direction. This set of circumstances becomes even more problematic when students with diverse needs rely on and are legally entitled to an equitable public education, so educators must expand their repertoire of skills and best practices effectively to address students' needs (Norton, 2001). To meet diverse student populations' needs, districts and teachers must work collaboratively and with families and communities to determine parameters and expectations for professional development goals and plans (Poole, 2000; Singleton, 2015). It is only “After educators begin engaging in this work personally, [that] they can collectively redefine and invent instructional practices that accelerate higher achievement of underserved student populations” (Singleton, 2015, p. 259). As a result, I also hypothesized that the IL ESSA further fails students 
with its stratification of schools (Finn, 2009). Indeed, Chalkbeat, in an article on ESSA accountability, argues underperforming schools are often the poorest and house many students with disabilities:

Nearly all of under- and low-performing Chicago high schools are on the South Side and sit in or border the city’s poorest census tracts. Some are staring down steep enrollment declines and teach a higher-than-average percentage of students with disabilities. (Burke \& Kunichoff, 2018).

This phenomenon is nothing short of educational apartheid (Noguera \& Syeed, 2020).

Being labeled as underperforming and given a direct message that the state will now control learning signals a loss of agency and a downgrading of teachers' expertise that is discouraging and dispiriting, making it all the less likely teacher performance and student outcomes improve significantly. Schools labeled as underperforming or failing are punished by public shaming, and additional and generally stifling oversight. When underperforming and failing schools then have professional development activities forced upon them, that professional development is not engaging, timely or relevant. As a result, difficult conversations such as those about race and social class inequities may never come up among educators who most need to have them. Professional development activities that reinforce dominating ${ }^{1}$ white cultural themes like politeness then mean the conversations that appear to some to be impolite, but are actually just challenging, may never come up, key because every racial group needs to address equity issues.

\footnotetext{
1 "Dominant” was intentionally replaced by "dominating” as a descriptor for oppression and dominance of one group over another.
} 
Even the Network's name, IL-EMPOWER, implies state and federal governments retain sovereign power and knowledge, dispersed to schools. IL-EMPOWER Network partners are established via an online application to ISBE outlining capacity and resources as a learning partner in one or more of three categories: Governance and Management, Curriculum and Instruction, or Culture and Climate. In their description of the Network, ISBE claims,

This new structure replaces the single-provider model currently in place and empowers schools with greater choice and collaboration that is informed by data assembled through a needs assessment and equity analysis. IL-EMPOWER promotes collaboration and peer-to-peer learning as vehicles for educator-led and state-supported school improvement. (Support and Accountability: IL-EMPOWER, 2018)

While ISBE uses such terms as choice, collaboration, educator-led, and state-supported in their promotion of the Network, the policy directive contradicts language suggesting the process is inclusive or collaborative. After working with schools, IL-EMPOWER-approved providers are expected to report back to ISBE regarding the completion of professional development initiatives. Even if providers were not required to report back to ISBE on what specifically they surveilled, the sheer presence of providers along with requirements providers use their expertise and oversight as state-approved providers are enough to control behavior, control conversations within the collaboration, and send the message to educators that the state is better knows teachers' learning needs. This type of state control and surveillance challenges teachers' professional expertise, judgment, and agency and causes educators to lose self-confidence, be humiliated, or become disengaged from the learning process (Bill \& Melinda Gates Foundation, 2014; Breneselovic \& Krnjaja, 2012; Calvert, 2016). 
ISBE drafted the IL ESSA in response to federal ESSA requirements. According to federal legislation, each state must submit an ESSA plan for approval to be eligible to receive federal funding. I argue that because the intended audience for the IL ESSA is the federal government, the discourse used is prescriptive, punitive, and expresses the state's power exercised over local schools. Using a critical lens to read a policy text allows underlying narrative intent to emerge for study and critical analysis. The policy's discourse, or use of language, can reinforce or corrode a text's intended message, important because discourse might negate a policy's intended purpose. My analysis offers opportunities to improve policy language and implementation based on accepted best practices in the area of professional development (Bill \& Melinda Gates Foundation, 2014; Calvert, 2016). I offer a reflection and a critical review to suggest improvements in the power dynamic the policy spotlights between the state and individual schools and educators. Because the most effective professional learning relies on educators feeling valued and having input (Bill \& Melinda Gates Foundation, 2014), my analysis of this policy offers suggestions to improve professional development and, by extension, learning outcomes, by illuminating and analyzing inequities the policy language creates and enforces. My analysis raises inequities to the surface and challenges ineffective ways and means of delivering professional development so state policies such as the IL ESSA might become useful, critical, and tailored to the community rather than fragmented, punitive, and humiliating. 


\section{CHAPTER II: REVIEW OF THE LITERATURE}

\section{Introduction: Content, Scope, and Organization of the Literature Review}

I begin my review of the literature with an historical overview of adult learning and professional development so my readers might better understand the evolution and needs of educators. As professional development for practicing educators has evolved, its designers have progressed from considering educators as actors trained to follow a script, to the need for educators to engage in reform activities, to the value of collaboration, data analysis, and formative assessment. This progression has been documented and studied by researchers who primarily have focused on satisfaction or self-reported anecdotal information from educators regarding what learning they find most compelling.

To allow my reader to understand the history of professional learning, I outline and identify themes researched in the field over several decades. Since the focus of the IL ESSA is on currently practicing educators rather than those in pre-licensure programs, I purposefully concentrate on the field of professional development, as opposed to the field of teacher preparation. I designed the scope of my study intentionally to illuminate work that happens within schools and with teachers currently serving in classrooms. I mean this historical review of professional development and learning to offer a foundational perspective into presently accepted best practices and to provide essential context for my policy analysis.

\section{The Evolution of Professional Development}

As long ago as the late $17^{\text {th }}$ century, educators considered learning the result of experience and skill practice. Students were seen as a blank slate upon which experiences would define an individual's knowledge (Locke in Taylor \& Hamdy, 2013). Building on that concept, it was later theorized that learning occurs due to positive experiences and repetition (Thorndike in 
Taylor \& Hamdy, 2013). The school system struggled with these expectations, finding it necessary to create uniform learning criteria by which all students could be measured and thereby equally be prepared for the workforce. No longer could institutions devise their own instruction and curriculum based on local criteria. An education system was developed by which students would pass through specific stages from elementary schooling to secondary and then higher education (Goodman, 1976). Teachers of each system were responsible for determining which students could continue to the next phase (Goodman, 1976). The post-World War II period defined a new era of concern for public school systems by the federal government. The 1957 Russian launch of Sputnik prompted U.S. citizens to a crisis of confidence in U.S. public schools; the public called for sweeping change to meet the space race's demands. Subsequently, the National Defense Education Act of 1958 (United States, 1964) ushered in a complete overhaul of U.S. public education. The government directed millions of dollars to mathematics and science to increase the number and quality of future scientists (Goodman, 1976). This call for educational innovation evolved into an ever-changing menu of failed innovations that trailed throughout the following decade (Sarason, 1996). Educators came under pressure to change what they were teaching as well as the ways they were teaching content (Goodman, 1976).

Expectations for teachers' knowledge and ability reliably to produce strong student outcomes subsequently escalated, so "Trained teachers and administrators would not only command a knowledge of the subjects taught but also of the procedures for conveying the information and skills and for evaluating the progress of the students” (Goodman, 1976, p. 10). This more systematic approach to instructional delivery required teachers to share common pedagogical and subject-matter understandings and be sufficiently prepared for instruction and assessment tasks. As the focus on improving teacher performance escalated, specific research 
studies by adult learning theorists represented significant progress in defining differences between adult learning, or andragogy, and a child's learning while a student, or pedagogy (Taylor \& Hamdy, 2013).

In the 1960s, Malcolm Knowles (1973) first coined the term andragogy to describe unique processes by which adults learn. The underlying assumptions of andragogy include an understanding that as humans mature, they become more independent, self-confident, and selfdirected. Adults, therefore, need to be seen and valued as self-directed individuals in the learning environment. Knowles theorized that reverting from seeing adult learners as autonomoustreating the adult as a child would be taught—results in an internal clash between an adult learner's maturity and a child-like pedagogical approach. The adult then becomes resentful, which conflicts with the ability to learn. Knowles’ theory of andragogy also details how adults come to learning with a wealth of experience that must become part of the learning process. Because they possess an extensive experiential background, adults must be involved in active learning instead of passive participation in such traditional pedagogical techniques as lectures. Active participation in learning experiences is therefore seen as best practice for adults, privileging such techniques and methodologies as action research, experimentation, team projects, and problem-solving (Knowles, 1973; Taylor \& Hamdy, 2013).

Puzzlingly, knowledge and theory of adult learning were not typically applied to teachers’ staff development activities. In 1997 Hilliard argued, “There is a critical problem with the deep structure of staff development in its traditional form-it cannot produce teachers who are routinely successful” (p. 28). Too often, teachers were treated not as thoughtful learners who ought to construct their own meaning but as passive participants. In light of theoretical advances in adult learning, Lieberman (1995) proposed, 
What everyone appears to want for students—a wide array of learning opportunities that engage students in experiencing, creating, and solving real problems, using their own experiences, and working with others—is for some reason denied to teachers when they are learners. (as cited in Sparks \& Hirsh, 1997, p. 591)

Professional development of the late 1990s was still most often defined as half-day, fragmented learning activities during which teachers in groups passively listened to a variety of speakers disseminate information on disjointed, unrelated topics (McAdamis, 2007). During this era of professional learning, across staff development sessions activities were fragmented, based on individuals' perceived needs, conducted away from the classroom setting, and focused on generic instructional strategies (Sparks \& Hirsh, 1997). Participants evaluated sessions mainly on personal satisfaction, as measured by a survey given after the workshop (Sparks \& Hirsh, 1997), called, euphemistically, a "smile sheet.” Although districts dedicated time and funds to the effort, teachers' attitudes, beliefs, and practices seldom changed via such learning activities. A significant indicator of strong student achievement is a teacher's effectiveness (Rhodes \& Beneicke, 2002). Therefore, student achievement was not affected in intended ways.

Around this time, staff development topics often continued to be chosen by central office or building administrators and consisted primarily of one-shot, brief workshops, or seminars (Choy et al., 2006). Professional development at this time was an event during which the presenter or self-proclaimed expert imparted information to the participants (Sparks \& Hirsh, 1997). Teachers were passive participants who often struggled to find relevance to the workshop setting or topic. Additionally, handfuls of teachers sought completion of university courses, but few courses were relevant to schools’ issues. Some professional development activities resulted 
in sustainable change or implementation of best practices, but some did not (Sparks \& Hirsh, 1997).

The 1990s brought a change in thinking concerning professional development and research findings on best practices in adult learning. Educational leaders advocated for change, suggesting traditional workshops lacked continuity and so could not prepare teachers to meet students' needs (McAdamis, 2007). The focus of professional development shifted from a presenter on stage who was the purveyor of knowledge to the engaged adult learner able to help determine his or her own learning path. As a result, more effective practices began to be embraced by educational leaders and school districts in the late 1990s (Sparks \& Hirsh, 1997).

According to Sparks and Hirsh (1997), these shifts in the field's philosophy of highquality professional development evolved to include a new focus on learning processes. Staff development designers began focusing on individual and systems improvement rather than solely on individual-level improvement since research made it clear the organization's success depended on concurrent supports offered throughout the system (Sparks \& Hirsh, 1997). This shift in professional development also created less of a fragmented effort and less professional development based merely on trendy innovation, which typically provides little research to back up effectiveness. A new strategic focus with a shared vision and measurable objectives yielded an inclusive approach to change.

Another factor in the paradigm shift of the 1990s was a new concern for school improvement goals. The quality of staff development shifted from being measured by the number of hours educators would sit through training to focus squarely on student outcomes (Sparks \& Hirsh, 1997). Expanding on typical, basic instructional-strategy topics, staff development also evolved to address more content-specific skills based on research regarding 
teachers' needs not only to understand strategies such as cooperative learning but also to show mastery of their specific content area, such as language arts or math (Sparks \& Hirsh, 1997).

Finally, this professional development paradigm shift ushered in a stronger focus on jobembedded staff development extended throughout a district. In the new model, those who offered staff development were consultants and facilitators rather than trainers. Professional development then could be focused on continuous learning at every level of the system, from teachers to board members and administrators. A shift away from the previous training model to daily learning during the school day gave teachers credit for being thoughtful and intellectual masters of the curriculum rather than technicians expected to follow a script (Little, 1993). Such a model provides continuous learning opportunities unconstrained by a workshop’s predetermined start and end times. The new focus on continuous learning became critical to professional development's success because “teachers may learn a new instructional skill but find that their use of it gradually diminishes because no one else in the school is using it or because their principals do not support the practice” (Sparks \& Hirsh, 1997, p. 17).

Despite research findings and the accompanying theoretical paradigm shift in professional development, during the early 2000s, staff development topics continued to be chosen by central office or building administrators, and consisting primarily of one-shot, brief workshops or seminars (Choy et al., 2006). Professional development remained an event during which information was imparted to participants by a presenter or self-proclaimed content-expert (Sparks \& Hirsh, 1997). Teachers largely remained passive participants who often struggled to find relevancy in the workshop setting or topic.

The introduction of Professional Learning Communities (PLCs) ushered in a large-scale material change in professional development. In the early 2000s, the education association 
National Staff Development Council (NSDC), later renamed Learning Forward, published many articles and offered numerous conferences on the topic of PLCs, a term coined as early as 1960 but made popular in the 1990s and 2000s by Richard DuFour and Robert Eaker (1998). The movement outlined conditions for success, including collaboration, time allotted for learning, data use, and leadership (Hord, 2009).

Since the year 2000, many high-performing districts have moved away from professional development workshops delivered to large groups without regard to individual needs and a PLCbased system of job-embedded professional collaboration (Penuel et al., 2007). PLCs focus on small groups of educators established to learn from and with one another and to collaborate on content through continuous dialogue based on timely issues. In PLCs, collaboration occurs teacher-to-teacher and teacher-to-administrator, but an individual's position is secondary to the conversation (Danielson \& McGreal, 2000). In the PLC model, educators no longer view professional development as something they go to or have done to them. Instead, they are actively involved and invested in a culture of collaborative learning based on individual needs and linked to specific outcomes. Danielson and McGreal (2000) theorize the result is transformational learning that alters teachers' behavior, beliefs, and motivations.

The advent of the PLC-type collaboration is significant because supported conversations with peers in a trusted relationship significantly improve teacher performance (Rhodes \& Beneicke, 2002). Learning is a social activity (Taylor \& Hamdy, 2013). Adults are unlikely to be receptive to professional development when they feel manipulated (Rhodes \& Beneicke, 2002), so an evaluation of performance should include a teacher's individual self-assessment (Danielson \& McGreal, 2000). The performance appraisal evaluation instrument serves as a model of expected performance. "By providing an agreed-upon framework for excellence, a framework 
for teaching serves to structure conversations among educators about exemplary practice” (Danielson, 2007, p. 6). Such exemplary practice includes formative assessment results or specific feedback about performance based on evaluation expectations. Assessment data is provided to teachers so they may use it immediately to improve their practice (Danielson \& McGreal, 2000). This type of self-guided learning in an organization leads to improved teacher performance (Rhodes \& Beneicke, 2002). Teacher agency gives adults the opportunity to direct their own professional learning and therefore be more engaged (Calvert, 2016).

In the years following, from 2010 to the present, a new focus has emerged concerning professional development due to research on the use of data to make timely, well-evidenced improvement decisions for a classroom, school, and district (DuFour et al., 2008). Thoughtful use of assessment data is crucial to collaboration activities in a PLC model (DuFour \& Eaker, 1998). However, Ricken (2011) cautions against seeing PLCs as a silver bullet or emphasizing the application of the initiative instead of the need to improve student achievement. "When the mission itself becomes implementing PLCs, student achievement becomes, at best, an afterthought” (Ricken, 2011, p. 160). Ricken finds this especially true in the case of high-poverty schools. Economically challenged schools approach PLCs differently than their middle-classschool peers. "PLCs enacted within high-poverty, low-performing schools do not identify upward social mobility or the goal of racial and social class equity as an overarching mission because classroom practices and social factors collectively influence goal-setting of teachers and school leaders” (Ricken, 2011, p. 164). Therefore, work done in collaboration merely serves to maintain the status quo rather than confronting social mobility or equity issues (Ricken, 2011). For this reason, Ricken argues the PLC model should not be embraced as the only or even as the 
most effective model for school improvement, especially in schools whose communities suffer from high poverty.

\section{Review of Research}

"Professional development must be constructed in ways that deepen the discussion, open up the debates, and enrich the array of possibilities for action” (Little, 1993, p. 22). Like youth learners, adults want the opportunity to make decisions and learn through problem-solving and hands-on experiences (Knowles, 1973). Adults need to understand the lesson’s connection to their world and be able to apply the information immediately. They need to know why the new knowledge is essential and how it applies to their needs (Knowles, 1973). As a result, selfassessment is a powerful catalyst to self-directed professional development. When given the opportunity, in a secure and trusted environment, adults will most often accurately choose the areas upon which they need to focus (Danielson \& McGreal, 2000). The adult should therefore be allowed to design learning objectives. In a self-directed model, "the learner is likely to resist unless he chooses them as being relevant to his self-diagnosed needs” (Knowles, 1973, p. 114). In this model, the adult learner assumes a higher level of autonomy, agency, and responsibility (Danielson \& McGreal, 2000).

A teacher's individual self-assessment should include input from an administrator based on feedback from the evaluation instrument (Danielson \& McGreal, 2000). The evaluation instruments serve as a model of expected performance. "By providing an agreed-upon framework for excellence, a framework for teaching serves to structure conversations among educators about exemplary practice” (Danielson, 2007, p. 6). Formative assessment information, or specific feedback about performance based on the evaluation expectations, should be provided to teachers so they can immediately improve their practice (Danielson \& McGreal, 2000). 
Regardless of a teacher's experience or expertise level, it is essential to outline expectations for performance and growth (Danielson, 2007).

\section{Gap Analysis}

My review of the literature supports the need for collaboration, but there is no literature yet on the IL ESSA and its discourse as it aligns to recommended practices. Current research suggests adults, just as student learners, want to be active in their learning, choose their study, and make practical application to their learning. Collaborative learning activities can meet those criteria, but leaders must also explore the quality of collaboration. Because low-level collaboration activities do not challenge critically teachers' practices or philosophies, they cannot involve risk-taking, instead offering only a comfortable level of collaboration. Such activities prove shallow and insubstantial, and research finds they seldom lead to noteworthy advancements or changes in the teachers' routine or pedagogy, rather only serve to maintain the status quo (Fallon \& Barnett, 2009b). Because the adult learning process is nonlinear, instruction should be interactive and suffused in connecting teachers' prior knowledge. Instruction should include learners' opportunity to make meaning as those who deliver professional development pose questions in a natural, interactive manner. Rather than a recitation-style lecture, lessons should allow learners to find relevancy in new knowledge (Brooks \& Brooks, 1993; Null, 2004). Lieberman (1995) begs, “The conventional view of staff development as a transferable package of knowledge to be distributed to teachers in bite-sized pieces needs radical rethinking” (p. 595). Such a narrow view of teachers' ability to make meaning does not align with effective practice research.

Little says forms of low-level collaboration "may provide teachers with collective permission for poor performance and marginal commitment” (as cited in Fallon \& Barnett, 
2009b, p. 4), a damning appraisal indeed. Such low-level collaborations are shown to be insignificant to learning outcomes and only serve to perpetuate teachers’ current practices because they offer validation, compassion, and unearned approval or support. They also deter teachers from engaging in more powerful, assessment-driven collaborations about improving practices because teachers waste time in low-level, collaborative activities (Fallon \& Barnett, 2009).

By contrast, when teachers engage in joint work (Little, 1990), the most effective type of collaboration, they do not marginalize or buffer criticism of failed attempts. Joint work includes such learning activities as mentoring, team teaching, co-planning, action research, peer observation, and coaching. This type of collegial activity spreads responsibility across the organization and invites far more reflective dialogue and inquiry. Research shows this is the most likely form of collegial work to create considerable improvement in teacher performance and student outcomes (Fallon \& Barnett, 2009b). It requires a safe environment within which a learner can reflect critically upon previously held mental models or philosophies.

Every student in every district, regardless of socioeconomic status or background, deserves highly effective teachers' very best instruction, not merely highly qualified teachers. The literature contains an abundance of research on the effects of external forces on student achievement, and it is important to determine the influence of professional learning on all aspects of a complex organization. More importantly, a policy as influential and prescriptive as the IL ESSA must purposefully draw attention to the need for professional learning guided by knowledgeable leaders or peers.

If the design of PLCs included joint work (such as mentoring, team teaching, coplanning, action research, and peer observation), coupled with a more experienced, 
knowledgeable peer (such as an administrator, coach, or a university professor), the system could become more effective. This type of schoolwide collegial activity (Taylor \& Hamdy, 2013) allows for more reflective dialogue and inquiry, based on assessment results and research, so it is the most likely form of collegial work to create considerable improvement (Fallon \& Barnett, 2009b).

Schmoker (2006) asserts, “The single greatest determinant of [effective] learning is not socioeconomic factors or funding levels. It is instruction” (p. 7). Thus, administrators must recognize the importance of quality, unfragmented professional development. Every dollar or minute wasted on ineffective PD activities negatively affects the educational process for staff member and student alike. No longer can districts settle for mediocre professional development activities that merely meet a teacher's recertification requirements (Penuel et al., 2007). As a field, we must demand more and plan for it with strategic fervor. This dilemma represents a moral and ethical challenge for educators.

Despite the abundance of literature on best practices in professional development for adult learners, there is a paucity of research on the way in which such plans as the IL ESSA governs professional development. The IL ESSA is a contemporary document that purports to improve performance. However, there is a gap between educational theory and research and the policy’s discourse. Specifically, Daloz (in Galbraith, 1998) indicates adults reject professional development when power is misused or their relationship with the person delivering the information lacks trust.

Professional learning must provide the largely white U.S. teaching force with more than access to buzzwords or trendy topics. It should include learning that disturbs whiteness, learning that refuses to be colorblind, learning that makes people uncomfortable, and learning that 
exposes and challenges social systems that create and uphold systems of oppression. Such professional learning should provide opportunities for teachers to learn from perspectives other than those they inhabit by virtue of their assigned social categories at birth. Demographically the majority of teachers are white, middle-class females (Shedlow, 2017), so many lack experiences that can provide perspectives and thoughtful, critical understandings of racial inequality, injustice, and social systems that reify oppression. When a white, middle-class teacher does not receive thoughtful, critical professional learning on diversity, equity, and inclusion, they often only have knowledge of "others" that allows them to fall back on deficit-based discourses, falling into such equity traps (McKenzie \& Scheurich, 2004) as claiming parents of Black children do not care about their children's education. Equity traps give white teachers neat excuses for not serving all children equitably and thoughtfully. When professional learning reinforces equity traps, that learning makes and reinforces inequitable thinking and pedagogical practices of educators, when what is required is that white teachers become uncritical or settled in their negative attitudes of parents based on their socioeconomic status, the darkness of their skin, or their language status. Poor professional learning then further hinders teachers' abilities to address equity issues, or “traps” equity (McKenzie \& Scheurich, 2004).

Because the topic of injustice is not one with which most white, female educators are familiar, those teachers then largely feel uncomfortable addressing and are unwilling to address racial and socioeconomic deficit thinking on their own. They use equity traps (McKenzie, 2004) to make excuses for injustice. In addition to conversations and training, professional learning should allow teachers to experience classrooms where students of color are successful (McKenzie \& Scheurick, 2004). 
Contemporary approaches to professional learning highlight areas seen as best practices and can subsequently get hung up on trendy topics such as social-emotional learning and grit. Topics such as "grit" are part of an equity trap because it is assumed that poor, Black and brown students could achieve, if only they were taught or encouraged by their families to try harder. This belief is not only dangerously colorblind, but completely ignores and covers social systems designed to oppress based on race, socioeconomic status, immigration status, etc. In U.S. schools a focus on character education and responsibility, hard work and positive attitude have replaced a focus on civic education (Love, 2019), turning from current events, history, law, geography, and economics to a focus on preparing students to comply, and to affirm their compliance and hard work in order to achieve The American Dream, but no amount of a student's hard work is enough to challenge or defeat systems of racial or socioeconomic oppression.

Contemporary professional learning therefore often only succeeds in normalizing students to comply and not question, especially Black and brown students who are underrepresented by school staff and textbook authors. Setting out to spotlight the struggles of Black and brown students, and the need for educational freedom established with love, creativity and “mattering,” Love (2019) points out how professional development gets hung up on buzz words or quick-fix topics. The field of education is uses quick fixes, slogans, and gimmicks to build pre-packaged professional development and seeks to identify a silver bullet of educational reform that will fix all students in all schools. But such fixes fall woefully short of addressing needs of Black and brown students in particular because they do not confront systemic injustice (Love, 2019).

Teaching strategies and education reform models must offer more than educational survival tactics to tactics to dark children—-test-taking skills, acronyms, character 
education, No Child Left Behind, Race to the Top, charter schools, school choice. They need to be rooted in an abolitionist praxis that, with urgency, embraces what seems impossible: education for collective dignity and human power for justice. (Love, 2019, p. 13)

Equity traps, or individual and collective patterns of thinking, prevent educators from believing Black, brown, poor, and immigrant students can achieve at the same level as their white peers. Equity traps are conscious and unconscious thinking used to blame educational failure not on teachers' failures, but on on students and families through assumptions that Black and brown students cannot achieve at the same level as white students (McKenzie \& Scheurick, 2004). Educational policy can make a positive change if not used to blame, and subsequently defund public education or discredit schools.

Trying to change the minds and practices of educators requires a steadfast and strategic approach to professional learning. It is not enough to make excuses or place blame with equity traps. Not only is there a gap in how professional development works to identify the equity traps, but in how professional learning can effectively address equity traps and deficit-based discourses.

Whitestreaming forces a standard of White history, values, and norms for the entire U.S. society, specifically in schools via curricula and pedagogy (Urrieta, 2004). Whitestreaming creates an environment of doubt and low expectations for students and assumptions of parental disengagement, based solely on race (Urrieta \& Martinez, 2011; Urrieta, 2004). Strong, critical professional development makes white educators feel uncomfortable because it draws out injustice and challenges prior held beliefs such as whitestreaming. Professional learning can be designed to help educators unlearn or consciously disregard these previously held 
misconceptions and embrace positive approaches rather than oppressive, discriminatory approaches. 


\section{CHAPTER III: METHODOLOGY}

\section{Introduction}

Critical discourse analysis allows the opportunity to uncover, study and challenge social inequalities and dominating power structures (van Dijk, 1993) of one social group over another in talk and text (van Dijk, 1995). This influence of actions or minds of a dominating group over another can take the form of power abuse or influence via patterns of discourse or access to discourse, such as in state officials who have access to policies that control or influence the less dominating (van Dijk, 1995). Gee (2011) thinks all discourse analysis should be critical discourse analysis, given that all language is political. In this study I employ critical discourse analysis as my methodology using Foucauldian theoretical concepts to build my theoretical frame through which to expose the ways in which the Illinois State Board of Education (ISBE) establishes indirect dominance over educators via the IL-EMPOWER Network as articulated in the IL ESSA. I further argue discourse can thereby create a denial of individual educator agency and undermine confidence in a teacher's professional expertise.

The target audience for a document, or policy, often influences how it is drafted. The flyer drafted by ISBE for districts better to understand the IL ESSA utilizes phrases such as "invites schools to examine" and "determine their levels of performance, to identify the most impactful [sic] focus” (ISBE, 2018). In contrast, the ISBE plan submitted to the U.S. Department of Education (USDOE) includes phrases such as "The LEA will be supported in establishing a strong program monitoring system to ensure that the selected practices are implemented with high levels of fidelity” (p. 93). The differing, opposing discursive practices represented in the two documents provide a glimpse into the indirect dominance placed on districts. One document “invites” participation while the other “ensures” compliance (ISBE, 2018). 


\section{Research Method}

Discourse analysis offers a methodology through which power at play can be illuminated, evidenced, and analyzed (Wodak \& Meyer, 2016). The power may be legitimate or legal (van Dijk, 1995), such as the control of a courtroom by its judge regarding sidebar discussions or conversations. But it can also be counter-productive or even harmful. "Language is a key way we humans make and break our world, our institutions, and our relationships through how we deal with social goods” (Gee, 2011, p. 9). Discourse analysis does not merely describe language. Instead, it goes further to identify and analyze themes within text and talk and then offer that analytic output to the field (Gee, 2011). Discourse analysis can take on and dismantle nameless text from institutions, such as with expressions in a policy (Gee, 2011).

Those who conduct Critical Discourse Analysis (CDA) consider the talk or text of elite power groups and its limitations on the freedom of others less powerful (van Dijk, 1995). “That is, CDA specifically focuses on the strategies of manipulation, legitimation, and the manufacture of consent and other discursive ways to influence the minds (and indirectly the actions) of people in the interest of the powerful” (van Dijk, 1995, p. 18). The goal of the social institutions is to maintain social order and to preserve the power structure (Foucault, 1995). Those in positions of power, such as policy writers, often can determine the influence or control a discourse may have on groups under their control (van Dijk, 1995). As policy writers and government officials, educators generally presume these authors have status or credibility. This higher status and credibility translate to mind control or influence via discourse (van Dijk, 1995). CDA provides insight into how power elites, specifically agents of the state, use properties of text to influence and emphasize its social position for the less powerful, the educators, to align to the elite's goals (van Dijk, 1995). CDA allows the illumination of how those in positions of dominance can 
control the minds or influence those less powerful (van Dijk, 1995). “That is, powerful social actors not only control communicative action but indirectly also the minds of recipients” (van Dijk, 1995, p. 21).

In this study I critically analyze the discourses of the IL ESSA and supporting documents for conscious or subconscious discursive choices designed to construct, maintain, and legitimize the expression of power or dominance over schools and educators (van Dijk, 1993). My analysis of the IL ESSA offers a critical discourse analysis, analyzed through a Foucauldian theoretical frame, of the Illinois Every Student Succeeds Act (ESSA). To begin with I coded the ESSA plan's text better to understand the policy's authors' intent and discursive choices. My analytic methods have been organic and guided by the policy’s language.

The critical discourse analysis I performed on the Illinois ESSA was "not...ad hoc, individual or incidental, but general, structural and focused on groups, while involving power relations between groups” (van Dijk, 1993, p. 253). My analysis alternates from language and text to context and back to the text again better to understand the background of the policy (Gee, 2011). I analyze the power relations between groups of stakeholders, the intent and desire of each group, and the way in which the discourse maintains or expands the dominance and the will of the state over educators.

Critical discourse analysis, CDA, provides a lens into structures of dominance created consciously or subtly as a social practice, a structured hierarchy, or an understated norm (van Dijk, 1993). CDA is the study of discourse in social arrangements, power, and dominance, used to control groups and the resulting adverse effects and social inequities (van Dijk, 1993). It is used to study how language can be used by those in power to control the thoughts or actions of a 
group not in power (van Dijk, 1993; 1995). The larger the group, or the more people influenced by the discourse, the more authority or influence a discourse has (van Dijk, 1993).

My use of CDA allows the revelation of the discursive maintenance of dominance, influence, or exercise of power (van Dijk, 1995, 1993) not only through linguistic use, such as word choice but in grammatical phrasing or those interconnections as shaped by social practices (Fairclough, 2012) from the point of view of Illinois educators and educational leaders. I maintain it is important to reveal and begin to understand how the IL ESSA discourse propagates the sociopolitical elite's dominance, which I analyzed through such elements as figures of speech, tone, syntax, and semantics. A text's expression of social power may be subtle or understated, but for it to be considered power or dominance, violations must be generalized rather than sporadic (van Dijk, 1993). Therefore, the critical discourse analysis I perform includes a review of the recurrence or regularity of such rhetoric. I chose the critical discourse analysis process to allow a more thorough analysis as questions arose during my close reading of the text. Vacillating between reading the text and posing questions of the text allowed me to provide a more comprehensive analysis. My methods included a kind of coding as “creating categories triggers the construction of a conceptual scheme that suits the data” (Basit, 2003, p. 144)

Those in positions of dominance hold social and political powers; in this case, those who hold the control are state and federal officials. Again, those in positions of power and dominance control access to the discourse (van Dijk, 1995). Methodologically, CDA holds the promise to illuminate power in which actions or thoughts can be controlled by one group and exercised over another (van Dijk, 1993): for example, control of time as experienced by patients whose doctors 
schedule access through appointments (van Dijk, 1993). Similarly, the IL ESSA controls the time educators spend on learning via their involvement in professional development sessions.

Critical discourse analysis has long been used to reveal and define power or dominance in action or enacted via cognitive control or the influencing of thoughts (van Dijk, 1993). Because cognitive control can be very subtle as part of an accepted and natural discursive speech, it can be challenging to identify (van Dijk, 1993) and glean meaning from. Scholars typically use CDA to investigate sociopolitical power abuse, such as that exercised by those who perform acts of racism or sexism. Often oppressed groups accept such dominance, allowing exercising of power to go unquestioned (van Dijk, 1993). The analysis I perform on the IL ESSA is designed to highlight the effects of the state's power exercised over powerless, highly surveilled educators. Given scholars' knowledge widely known about the need for educators to have control over their own professional learning (DeMonte, 2013), that the policy purports to offer choice, yet offers nothing of the kind, rather prescribes, proves a detriment to educators' professional growth. The fallout of this policy's implementation in practice disproportionately affects marginalized and underrepresented groups because the policy's Foucauldian wrath focuses on troubled and failing schools.

I measure the success of my critical discourse analysis by its ability potentially to produce change (van Dijk, 1993), specifically through revision to the IL ESSA policy or the drafting of future policy by allowing educators as stakeholders into the process. Van Dijk (1993) provides caution in claiming critical discourse analysis can achieve such lofty goals because "academic contributions may be marginal in processes of change, in which especially those who are directly involved, and their acts of resistance, are the really effective change agents” (p. 253). Nevertheless, my analysis of this policy is meant to provide a first step in uncovering and 
bringing the uneven power differential at work into the light. And, as the adage goes, sunshine is the best disinfectant. In this case, the change agents must be the agents of the state themselves, whom, in educational policymaking, are at the top of the hierarchical tier, and possess and exact substantial control over sanctions placed on educational organizations, both concerning the dissemination of funds and consequences or through publicly attaching labels of unsatisfactory performance to an educational organization.

A methodological goal of critical discourse analysis is that method's ability to reveal the level of access groups have to the discourse (van Dijk, 1993). As the dominating power elite, state agents have the broadest access to the IL ESSA discourse, as state agents are solely responsible for drafting it and then federal officials are solely responsible for approving the policy. In this dominating position, neither is likely to accept this assimilation of politics and educational policy (van Dijk, 1993), which could make effectuating change even more challenging.

\section{Theoretical Framework}

In this study, I set out critically to analyze IL ESSA policy discourse using the Foucauldian concepts of surveillance (via power or governmentality), normalizing judgment, and docile bodies to illuminate discrepancies between professional development best practices and the ESSA policy as well as to reveal discourses that create, reify, and maintain inequities. I begin by defining Foucault’s $(1995,2007)$ concepts of surveillance, normalizing judgment, the examination, and docile bodies.

Foucault, at once an anthropologist, historical archaeologist, and critical theorist, theorizes discourse as "a group of statements which provide a language for talking about—a way of representing the knowledge about—a particular topic at a particular historical moment” (as 
paraphrased in Hall, 2013, p. 291). Specifically, in his vast project documenting the history of the penal system and theorizing its far-reaching effects, Foucault (1995) maps the development of corporeal punishment through control of the body, control of the soul, and these processes' sociopolitical evolution, including the progression from control through physical torture of the body to control of the soul through omnipresent surveillance. In contrast to a tool possessed by individuals to torture or punish, Foucault (1995) perceives power as social and ever-present, wherein social systems and organizations are designed to exercise social control via surveillance which motivates most individuals to normalize their behavior to the established norm. Body politics are engineered using social organizations' training systems (the military, the prison, the medical clinic, the school, the factory) which tightly script and offer practice in corporeal docility, controlling those surveilled via the disciplining mechanisms of time, space, and movement (Foucault, 1995). According to Foucault, "the body becomes a useful force only if it is both a productive body and a subjected body" (Foucault, 1995, p. 26). Such power can be less direct than physical violence or force. It can be an instrument to establish physical and emotional order through the "political technology of the body" (Foucault, 1995, p. 26). The control of time, space, and movement creates docile bodies through repeated minor processes in response to a need such as "an industrial innovation, a renewed outbreak of certain epidemic diseases, the invention of the rifle or the victories of Prussia” (Foucault, 1995, p. 138).

Using devices such as timetables and drills or exercises, disciplining mechanisms control movements of the body over space and time to create docile bodies: obedient subjects, easily manipulated and analyzed through the creation of habits. The docile body is desirable because it is expedient and obedient: represented as the body of the soldier, not the body of the king, the sovereign. Disciplining mechanisms exercised through control of time, space, and movement 
make use of power held within a society rather than the imposition of a sovereign's power over his people. Foucault compares the docile body to clay waiting to be formed.

Foucault (1982, 1991, 2007) theorizes power relations exercised through sovereign power, disciplinary power, or governmentality, seeking "to create a history of the different modes by which, in [dominating, Western] culture, human beings are made subjects” (1982, p. 777). The reform of the criminal punishment system away from the focus of controlling the body to controlling the soul creates more efficiency through the use of disciplinary mechanisms rather than to make a more equitable process. Reform was initiated not out of concern with the welfare or treatment of prisoners, rather out of concern with the efficiency of power exercised over the general population with an aim to control. In contrast to the monarchial regime that focused on torture of the body as ceremony and dramatic display of sovereign power, the means of correct training control through constant supervision along the partitions of time, space, and movement, remaking the factory, military, school, and medical clinic into social organizations to manufacture and maintain docile bodies through the same means as does the prison.

As power is exercised on the social body rather than just the body itself, Foucault (1995) challenges contemporary societies to recognize and become critical of power structures, particularly those that appear neutral, independent, and part of the "natural order" of things (1995). In this type of power structure, a society relies not upon force to maintain social order; rather, it depends upon the imposition of a self-governing norm in which both a disembodied, figurative “panopticon” and individual citizens police one another in a kind of "snitch economy”: a system far more powerful and insidious than previous societies’ reliance on force enacted through torture and physical punishment (Foucault, 1995). “The historical moment of the disciplines was the moment when an art of the human body was born, which was directed not 
only at the growth of its skills, nor at the intensification of its subjection, but at the formation of a relation that in the mechanism itself makes it more obedient as it becomes more useful” (Foucault, 1995, p. 137). The docile body is intended to become a far more efficient and useful body and instrument of the state.

While social organizations such as the military or the school might seem politically neutral or absent political power, these institutions are not politically neutral since they are created and used purposefully to exert control and to educate through normalizing judgment. Normalizing judgment serves as a disciplinary mechanism through which whatever behavior does not meet the rule or departs from the norm is corrected. So all-encompassing are the social organizations' design to control behavior that even slight departures from what is deemed “correct” are punished. Normalizing judgment is designed to be persistent and pervasive within and across social organizations. A leader in the French post-structuralist intellectual movement, Foucault theorizes social organizations as complex sites of surveillance and discipline used to socialize a society’s inhabitants into effectively controlled, docile bodies.

A groundbreaking, influential subset of postmodern theory, French post-structuralism emerged as a literary and philosophical movement in reaction to and critique of French structuralism in the 1950s-1960s during a time of revolution, political uprising, a resurrection of feminism, and general disenchantment with value systems perceived as traditional. Structuralists maintained pre-determined, fixed meanings of the world were commonly held by all. Poststructuralist theorists challenged the underpinnings of structuralism, insisting ideas must be considered structurally as opposed to being considered in isolation. French post-structuralists such as Derrida, Foucault, and Barthes, were once structuralists yet came to reject most of structuralism's claims. In particular, they rejected the structuralist concept of a fixed relationship 
between the signifier and the signified. Post-structuralists challenge fixed meanings, instead offering that in order to understand an object, it is necessary to understand that which created the object. Therefore, the reader's interpretation of a text takes on importance over that of the author. Ultimately, post-structuralists theorize meaning is contextual and ever-changing, created by the reader's engagement with the text, not a fixed meaning imparted from author to reader. Consequently, every text has multiple meanings. In fact, Roland Barthes (1968) theorizes the author does not maintain authority as the prime source of a text's meaning.

Original to postmodernism, and in opposition to Positivism's claim to objectivity, is postmodernist theorists' epistemological focus on subjectivism. A subjectivist epistemology places great, ultimate value on the individual reader's interpretation of a text. Rather than the interpretation or meaning being solely created by the author, it is the reader who makes meaning: multiple meanings, multiple truths. Poststructuralist theorists also honor the context in which the discourse is created, whereby affecting the meaning made, dependent upon the context, historical implications, and the person receiving and interpreting the message.

A founding post-structuralist, Foucault's theory is important to understanding the workings of society because his work reveals the ways in which a society's members are preemptively controlled. Foucault theorizes Western society has become a disciplinary machine whose members are continuously monitored, observed, and examined by those in higher positions of authority who collect data and information and use that information to discipline in order to effect control. Society's members are disciplined as the mechanisms of normalizing judgment are applied to all, by all. In effect,

The judges of normality are everywhere. We are in the society of the teacher-judge, the doctor-judge, the educator-judge, the "social worker"-judge; it is on them that the 
universal reign of the normative is based; and each individual, wherever he may find himself, subjects to it his body, his gestures, his behavior, his aptitudes, his achievements. (Foucault, 1995, p. 304).

Foucault theorizes the means of correct training—hierarchical observation, normalizing judgment, and examination—are used as key instruments of social control. This disclosure is

revolutionary because previously, control was highly concentrated, disseminated by a sovereign or state; however, by implementing the means of correct training, a society's members monitor and apply disciplinary mechanisms, vastly extending the surveillance network to become compulsory, omnipresent, and omnipotent.

\section{Surveillance and Observation}

According to Foucault, the primary purpose of disciplinary power is to train individuals so they may be more easily, reliably controlled. Individuals are taught or trained to adhere to institutional expectations or standards through what he calls the means of correct training: hierarchical observation, normalizing judgment, and the examination. In a historical view of torture and power, once punishment of the criminal's body proved less-than-successful, given that the subject either died of physical torture or, surviving the ordeal, was released to society and therefore torture was deemed insufficiently motivating, the penal system was remade as a literal and figurative surveillance machine, a panopticon (Figure 1), designed instead to punish the soul in order to control everyday human behavior. Control is thereafter exemplified as a calculated gaze as opposed to enacted by physical force. Penal system reform became necessary because the spectacle of punishment to the body proved fallible (horses did not cooperate; subjects did not always die) and inspired revolution within the masses witnessing the spectacle. Such failures caused subjects to doubt the sovereign power; the king's subjects then came to 
doubt or question the social contract they believed they were given at birth— to pay the price of obedience to the sovereign in exchange for the king’s protection and love (Tillyard, 1959), a foundational organizing tenet of the Ptolemic worldview. Foucault theorizes this change to the penal system as far more malevolent and insidious than outright physical punishment of the body because punishment of the soul is subtle, concealed, less public, and therefore not commonly recognized, objected to, or protested by the masses.

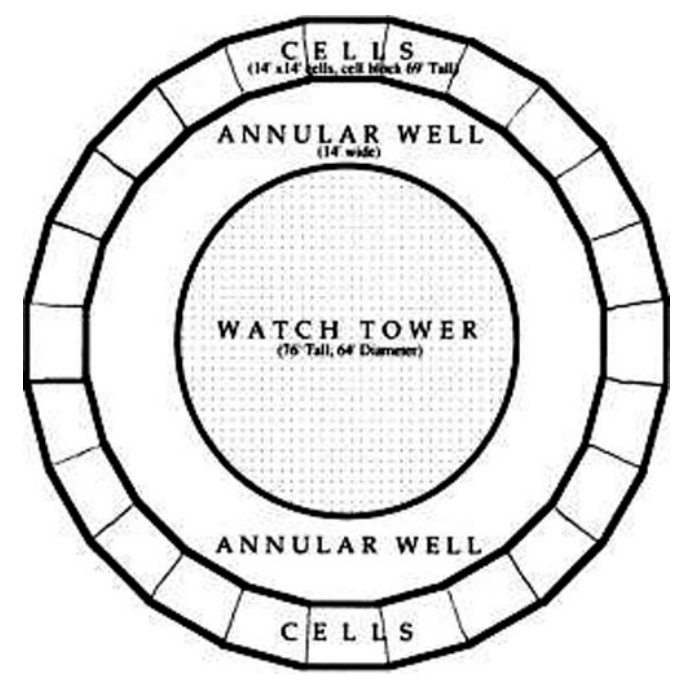

Figure 1: Panopticon design schematic, Jeremy Bentham (1791)

Operations of the body are controlled through mechanisms of surveillance and observation. Bentham's architectural panopticon design, a new prison architecture, features prison cells built around a central tower from which prison warders may conduct constant surveillance, putting prisoners under a "microscope of conduct" (Foucault, 1995, p. 173). The central portion of the panopticon consists of an observation tower where all inmates in all cells can be observed at all times, yet prisoners cannot see their observer: the prison's warders. By design, the warder does not have to occupy the tower- - the model is predicated on the threat of the warder's gaze rather than his actual gaze. Inherent in the panopticon's architecture, prisoners never know when they are being observed, and therefore are left to assume constant surveillance; 
this aspect of surveillance inspires and encourages self-governing behavior. It is a mechanism for “creating and sustaining a power relation independent of the person who exercises it” (Foucault, 1995, p. 2010). Within the panopticon's cell structure, a prisoner can neither see nor communicate with the warder or fellow prisoners, but can always and forever be seen.

Bentham's panopticon was designed for efficiency and utility so that subjects could be easily surveilled, and so all locations in which prisoners are housed are equally visible to prison warders from a central location. The architectural rendering of Jeremy Bentham’s panopticon offers literal representation of the figurative, omnipresent panopticon, which functions invisibly across society in order to normalize behavior to control individuals. While Bentham's panopticon was a literal architectural structure (though never built), its design exemplifies the figurative re-design of the prison (and society at large) into a prison designed not simply to punish those convicted of crimes but to remake the whole of society into a virtual surveillance machine. Consequently, throughout society, its members are theoretically observed and aware of that observation, even when the "warder" cannot be seen. Exercised and enacted across Western society, the training grounds for all citizens then occurred, by design, as a function of various social organizations: in the military, schools, factories, prisons, and medical clinics. Although powerful social tropes imagine Western democratic societies as free, the virtual panopticon regulates behavior in order to exercise control of the state through surveillance cameras, timeclocks, and reports. In such a society, the highly regulated, disciplined behavior of its members does not occur by individual choice, but rather individuals are socialized within social organizations to comply.

Broader Western society operates as a virtual panopticon. Even though most of the time no one who can enact consequences is actually observing or surveilling a driver, for instance, 
most people do not drive over the speed limit because a police officer could be watching, and consequences enacted and enforced. The ability of one of elevated standing to be able to control others based on a hierarchical position is controlling in a way that is more powerful than the threat of punishment or torture: the punishment of the soul, a highly effective mechanism of control as it creates and reinforces self-regulated compliance and conformity (Foucault, 1995). In doing so, hierarchical observation removes or at least impairs individual agency but does so under the guise of individuals' freely choosing to regulate behavior, even though that choice is in no respect free.

In this way, the figurative panopticon represents an authoritarian gaze that inspires the creation of docile bodies (Foucault, 1995), representing a full-scale social model of how people live under constant surveillance as a system of control (Foucault, 1995). It provides an example of how society goes about its day as if every individual is watched and thereby regulated, even if no watchtower or warder is present. Therefore, the social surveillance mechanism is built into the minds and souls of individuals; each person feels the gaze that operates as a vehicle of power. In this way, the supervisor or warder is invisible, yet power is automatic and omnipresent. A disciplined society is thereby created through passive surveillance used to exert control over not just physical bodies but souls. In this way, the soul is rehabilitated (Foucault, 1995).

Discipline's three prongs are surveillance, normalization, and the examination. Taken together, they powerfully control human behavior because not only are individuals subjected to the mechanisms, but they are also active participants in the maintenance and continuation of the system. Power does not merely repress, silence or hinder, a view of power that is too narrow; rather, it can be productive. "What makes power hold good, what makes it accepted, is simply the fact that it does not only weigh on us as a force that says no but that it traverses and produces 
things, it induces pleasure, forms knowledge, produces discourse” (Foucault, 1982, p. 119). It results not only in repression but also in privilege and reward.

Moreover, Foucault found human interaction and friendships to be a vital part of the analysis of power because of the need for desire and the need to please. While oppression and domination can result in an individual acting in ways he may otherwise not; a more powerful influence comes from a place of pleasure and desire. "Friendships or relationships that provide partners a sense of well-being, pleasure, and personal self-actualization could manifest a power that, as it grows in pleasure, could supersede the power of transactional, organizationally structured relationships (such as manager-subordinate) to shape organizational behavior” (Dixon, 2007, p. 290). Voluntarily established, mutually satisfying relationships prove more persuasive and dominating than relationships of those in a position of formal authority.

\section{Normalizing Judgment}

Omnipresent surveillance results in the normalization of human behavior. When observed and surveilled, individuals begin to conform or default to expected behavioral norms. Individuals perpetuate expectations of what it means to be a good student, patient, or soldier. Foucault theorizes normalizing judgment as a means of discipline and correct training as it uses reward and punishment to compare individuals or classify them against a standard. Deviations against the standard are corrected to conform individuals to behavioral expectations and to create homogeneity. Rather than such disciplinary power being instilled by a person or agency, it derives from an accepted standard of the majority of society, so all members are not just participants in but are complicit in upholding normalizing judgment. Foucault (1995) describes normalizing judgment as that which makes us do what we know is right and constructs our view of what behavior is considered "normal” and acceptable. 
Foucault (1995) chronicles the penal system's changes over the past two hundred years from a judicial power which relies on laws of the sovereign and state and exercised using external force, to an internalized normalizing power which regulates individuals through social organizations based on expected norms. Even though there is still a dominating, privileged class in Foucault's theory, power is then exercised through individuals in society rather than exclusively owned or bestowed upon a few. Unlike barbaric force or violence, the power of normalizing judgment is a very subtle yet effective instrument of control. For example, a prisoner does not need to be able to see the warder in order to be controlled by him. The mere acceptance of an omnipresent system of surveillance creates normalized behaviors among individuals who follow social expectations and norms. Another illustration of normalizing judgment occurs in schools. Foucault theorizes teachers and administrators monitor and control activity via the examination and the scheduling of activities as a means of pathologizing or making their practice somehow seem ineffective or unhealthy in an effort to produce change. This aspect of normalizing judgment is particularly important to my analysis because it can be used to illuminate the ways power is applied through normalizing judgment to the school system.

Normalization is the direct result of universal surveillance. Under observation from an authority, individuals conform to expectations. In this way, normalizing judgment instills discipline and a means of correct training. Normalizing judgment is that which makes us do what we know is right and constructs our view of what behavior is considered "normal" and acceptable (Foucault, 1995). Normalizing judgment is persistent and pervasive within and across social organizations. Society relies not upon force to maintain social order; rather, it relies upon the imposition of a self-governing norm. While social organizations such as schools might appear to serve in a neutral manner, they are not neutral because they are created and used to 
exert control and to educate through normalizing judgment, a disciplinary mechanism through which behavior is corrected when it departs from the norm or the rule.

\section{The Examination}

Teachers are regularly subjected to hierarchical observation and normalizing judgment through the "highly ritualized" function of the examination. The examination requires an action or performance to be reduced to something that can be measured. The examination is a “ceremony of this objectification” (Foucault, 1995, p. 187). In the examination individuals are surveilled using a multitude of collected data and documentation meant to repair individuals’ non-compliant behavior by comparison to a code of conduct or pre-established expectations. This data objectifies the individual when compared to a predetermined model. Examination serves to judge, classify, categorize and place individual traits within a hierarchy. In this way each individual is viewed pathologically: as a "case” that should be analyzed and classified as a means to correct, control, and dominate.

The examination offers a means of classifying, categorizing and hierarchizing individuals. Specifically, individuals are surveilled from a collection of data and documentation in an attempt to redirect behavior that does not conform to the norm or expectation. The data objectifies the individual when compared to the predetermined norm, much as in a comparison of the posture and body movements of a soldier who is expected to conform to very specific requirements, or a factory worker who is required to follow predetermined and prescribed task movements.

\section{Docile Bodies}

Foucault (1995) paints a picture of corporeal docility first by explaining how the body of the soldier is taught military control: head held high and erect with proper posture in uniform and 
with a slim and agile body. In the military organization, individuality and creativity are exchanged for consistency, uniformity, and the formation of a group moving together, disciplined, and in unison as a finely oiled machine. Through diminutive patterns of power and efficiency or "meticulous control of the operations of the body" (Foucault, 1995, p. 137), machine-like persons or well-trained troops are created and policed by use of the disciplining mechanisms.

Similar to a block of clay molded into a predetermined structure, the soldier is made, manufactured through the means of correct training, to fit a mold and is constructed to the military "standard," always prepared, and with an outward gaze. Through the means of correct training, the soldier's body is objectified and controlled, his individuality erased. This form of correct training aims to create useful, docile subjects and reform individuals to a corps that operates under a normalized, highly ritualized set of behaviors. Such routines, once enacted, nearly invariably create docile bodies. Even more powerful than sovereign power, where punishment is instilled by a few as justice for a crime, the creation of widespread docility makes individuals into a unit conditioned to act as one well-trained, obedient corpus. Foucault articulates how in this model of the social organization power is not only produced by those with privileged political or economic power as a Marxist view describes, but is also perpetuated by those subjected to the power. In this way, the means of correct training becomes even more influential on individual behavior than detainment in the penal system because while individuals appear to have agency, they are instead meticulously self-governed by an internalized set of standards and norms. The power exercised by social institutions creates docile bodies that adhere to its direction (Foucault, 1995). Individual bodies are rendered docile via control of activity as a result of such sequences of repetition and timing or scheduling of work (Foucault, 1995). 
Patterned rituals or sequential steps of expected tasks control behavior such as the expectation of work hours, scheduled lunch breaks, and tasks that must be completed by a deadline.

It is important to note that power exercised by those in positions of authority can be constructive if used to disseminate knowledge. Schools, prisons, factories, the military, and medical clinics should therefore not necessarily be seen as wholly negative aspects of a society if knowledge is being shared through them in ways that promote agency. To shift the discourse on policies to practice on professional development, policy writers will be required to recognize the passive, docile bodies that are created in policies that oversee via panopticon measures.

Deconstructing the model for oversight and accountability and empowering individual educators to take control of their own learning will be a more powerful approach.

\section{Justification of Theoretical Frame}

Discourse analysis is used to examine texts ("texts" taken in a broad interpretation of the term) and interactions in order to learn more about cultural and sociopolitical meanings by providing different ways of viewing or analyzing the world (Fairclough, 2012). "Discourse means anything from a historical monument, a lieu de memoire, a policy, a political strategy, narratives in restricted or broad sense of the term, text, talk, a speech, topic-related conversations, to language per se” (Wodak \& Meyer, 2016, p. 3). Foucauldian theory is a fitting frame to analyze the ESSA policy due to its focus on the nature of power and control, how power and control are exercised, and what end. Foucault (1995) theorizes power as a social construct in which people manipulate, use, defy, or operate around one another. The theoretical frame I employ I use to draw out those embedded power structures made explicit and analyzed within a social context in order better to understand how power is used to control and its effects. 
According to Foucault (1995), one’s awareness of surveillance stifles creativity and individuality. Using the means of correct training, omnipresent observation, and surveillance, and the ways the body and soul are bent to the norm, people end up acting, thinking, and believing similarly simply because they are subjected to constant surveillance, believe they are always being watched, and therefore feel the need to align behaviors to the norm in an effort to conform to an expected docility. Foucault (1995) refers to this as dynamic normalization which eradicates independent thinking because individuals tend to react to the ways they believe are expected rather than asserting their creativity, independence, and agency. What chiefly inspires this inquiry is my belief the IL ESSA sends Illinois educators the message they are incapable of directing their own learning, reinforcing abdication of creativity and learned expertise in favor of docility.

Power is the influence that causes individuals to do something they might otherwise not likely do. Post-structuralist theory is particularly useful for examining those oppressive power structures that seem to function below the level of everyday notice, relegated largely to systems thought to be part of "the natural order" of things and "just the way the world works." Compared to historical systems of violence and torture, modern systems of discipline punish through control of bodies in space and time using observation and discipline of the soul to reform human behavior. These power systems not only control offenders of the law but also rule the individual, law-abiding civilian (Foucault, 1995). When systems of domination, particularly those enacted through common social and organizational structures, function below human notice, the individuals constrained by these structures are oftentimes unaware of the breadth or depth of constraint, so make subconscious, rather than conscious, choices about their behavior reactive to the normalizing power being exercised over them. 


\section{Social Reproduction Theory}

Social inequalities between the haves and have nots, the rich and the poor, are replicated over generations. Across generations, inequalities are reproduced because of the inequities in financial and cultural capital or the lack thereof. Families of wealth or status have access to networks or cultural resources. Children of lower social classes do not have the same access to the social capital or cultural capital as do social elites. While a public education system is theoretically designed to reduce the gap that creates inequities between classes, if the system does not value the culture of the lower social classes as it does of the upper classes, the gap persists or widens. If students do not see themselves in or relate to the culture of their classrooms or curriculum, the inequities are not addressed, and students disengage.

\section{Researcher Subjectivities and Biases}

As a researcher, I come to this work as a former teacher, a superintendent, a mother, taxpayer, and an educational leader who has and will offer professional development. My past disappointments with professional development and collaboration as an educator influence my perspective on the topic. Similarly, the fact I have been let down by the promises of professional learning and collaboration shapes the way I approach and interpret the research. My prior experiences in poor quality, one-shot workshops, and story-telling collaboration activities guide my passion for this topic, as well as my analysis. My disappointment influences my approach to the research in the promises that are often made by policies that attempt to attend to social inequalities. Due to the nature of the policy analysis, the data is not intended to be the basis for generalizations about the quality of the policy or its general effectiveness. Rather, through this study I intend to illuminate challenges within the discourse presented by the IL ESSA. It is my hope highlighting and analyzing the IL ESSA discourse may inform future policy development. 
As an educational leader who has worked in PLCs and as a parent of school-aged children, I value the time educators spend outside of instruction but within their contractual workday. Teacher in-service time is one of the most valuable resources available to a school or district. Wasted minutes are a non-renewable resource. My experience and perspective on the topic influence the way I view the discourse presented as I have first-handedly observed the waste of this essential resource. I argue the creation of docile bodies within a school can create an idle environment at best, or at worst a resistant culture, both of which create a negative experience for students.

\section{Research Limitations}

The IL ESSA was written by state authorities with the intent to improve performance of troubled and failing schools, in particular, as measured by state assessments, mandated highstakes accountability measures. In my study I intentionally avoid exploring the mindset of the policy’s authors. My study is a policy analysis and therefore does not include interviews of the authors. My research, therefore, includes an imposition of theoretical categorizations and exogenous meanings specific to the discipline (Emerson et al., 2011). Absent the review of intent, my study is meant to illuminate the use of power within the IL ESSA through Foucault's theoretical framework. Because the primary purpose of disciplinary power is to train individuals so they may be more easily, reliably controlled, policies such as the IL ESSA are primarily designed to be disciplinary in nature. Via this policy and others like it, educators are taught to adhere to institutional expectations through the means of correct training, specifically hierarchical observation, normalizing judgment, and the examination.

The lens through which I analyze the power structures of the IL ESSA plan via Foucault’s surveillance, observation, and normalizing judgment is limited. Limitations 
particularly on race must be illuminated because I draw connections to racial injustice, but Foucault is a Poststructuralist who takes on structuralism. Due to this limitation, I employ the use of authors who focus upon how certain groups are minoritized. 


\section{CHAPTER IV: ANALYSIS OF DATA}

According to Foucault, the political operates as an authority that projects power via a "do what we want, but also how we want” approach. When state power operates in this way, the individual is controlled and is therefore transformed into a docile body through the use of three disciplining mechanisms: hierarchical observation, normalizing judgment, and the examination. Using the IL ESSA policy, the state employs disciplinary mechanisms to normalize and control the individual teacher to become efficient and effective to its demands; the specific processes of “improvement” are enforced by the parameters of the state’s examination. The IL ESSA's examination is far from apolitical, however, for it imposes a range of implications for teachers’ pedagogy, agency, and in the context of teachers’ professional learning: implications that create, reify, and reinforce inequities rather than serve to make Illinois public education a more just and equitable playing field.

\section{Omnipresent Warder via a Microscope of Data}

Section 4 of the IL ESSA policy incorporates tiered designations for schools, and the requirement of common, high expectations creates a microscope of conduct used as a disciplinary apparatus (Foucault, 1995). The state determines whether to impose its disciplinary apparatus via its use of state assessments that act as a mechanism for monitoring, documenting, and training educators. IL public school educators’ actions are therefore constantly on display and surveilled by the state, which result in educators' loss of control, agency, and professional expertise over learning outcomes and professional development activities. The pre-approved ILEMPOWER Network partners engaged as professional development experts for failing schools serve not as pedagogical advisors or helpmates, but as tools of state surveillance and punishment, specifically by the Illinois State Board of Education (ISBE). 
Through hierarchical observation by the Network, individual teachers' behaviors are controlled merely by the possibility of being observed, not necessarily by the observation itself, consistent with Foucault's theorization of the figurative panopticon under the warder's gaze. The warder's gaze is magnified by reporting requirements such as: "quarterly reports that provide data on progress in achieving identified targets," and the actual presence of the warder, "fieldbased staff who can, if necessary, provide technical assistance and monitor for compliance” (ESSA, p. 100). Foucault theorizes those controlled by being watched or by the threat of being surveilled voluntarily become docile. In such a system state power functions automatically because the individual never knows when they/she/he might be observed. When it comes to teachers in classrooms, docility comes at a cost of disengaged teacher learners who then make a perfunctory effort at professional learning rather than challenging their deeper value system, which is necessary effectively to address equity and subsequently improve student outcomes in troubled and failing schools.

According to Section 4, schools identified by the IL ESSA as “underperforming” and "lowest-performing” will be notified of a requirement to participate in the Network every three years and may only exit the IL ESSA's requirement to participate upon meeting specific criteria. The schools labeled in this way are most often the most underserved. Policymakers thereby control teacher movement, manners, and behavior in order to control activity and create docile bodies for obedience and efficient adherence to the agency's goals and its imposition of a good school/bad school dichotomy. Through the ESSA, the IL-EMPOWER Network serves as gatekeeper of professional learning topics and processes in schools deemed to perform below the IL ESSA's standards. If, as is commonly the case, the preapproved Network providers consistently belong to a racially and culturally privileged social class, difficult unlearning and 
destruction of deficit-based attitudes and actions are far less likely to be accomplished thoughtfully and justly. This inequitable aspect of the IL ESSA is especially troubling because critical equity work is left out and the voices of those already underserved and minoritized are sidelined or muted altogether.

Also of concern is teaching's categorization as a "professional" field based on its certified workers' ability to make decisions regarding students' direction, learning, and ethics. Policies, management influence, and political reforms systematically have reduced teachers’ autonomy and power to exercise agency in their work (Frostenson, 2015). Indeed, “teacher training and education has been subject to constant reform and change” (p. 22). Rather than enacting professional development meant to strengthen teachers' professional autonomy and agency, policies like the IL ESSA contribute to the formation and maintenance of a figurative panopticon in which educators become subjects to be molded, shaped, and disciplined. Those IL-EMPOWER Network policies and the management they are designed to enact instead dramatically reduce teacher autonomy.

While the state suggests it will support a school as it selects improvement plans, the IL ESSA states decision-making is owned by educators, not state officials. In reality, all topics are predetermined by the IL ESSA policy. While "The [Local Education Agency or school] will be supported in establishing a strong program monitoring system to ensure that the selected practices are implemented with high levels of fidelity" (ESSA, p. 93), state officials "support” the selection of criteria for improvement goals, thereby controlling, monitoring, and undermining educators’ professional judgment and expertise. More dangerously, the state’s control sends the message to educators they are incapable of making sound decisions with regard to their own professional learning targets. 
Illinois’ ESSA policy enacts Foucauldian disciplining mechanisms first by surveilling educators' movement through the omnipresent threat of the warder's symbolic gaze, and then by imposing the examination on low-performing schools resulting in identification of cohorts expected to receive Targeted or Comprehensive support over a period of three years. State-level education officials analyze individual schools' data to determine performance and "statedetermined exit criteria" and to impose "evidence-based practices for the purposes of school improvement” (p. 93). Specifically, in Section 4, entitled Accountability, Support and Improvement for Schools, the IL ESSA lists a set of ten indicators the state claims measure academic progress and unilaterally define success. But I argue it is wholly insufficient to impose targets of success; equity requires more than a unilateral definition of success. Furthermore, equity and inclusion require greater, more thoughtful action than simply the opening of doors (Valli, Cooper, \& Frankes, 1997). Teachers in poor schools, rural schools and those whose students are disproportionately marginalized or minoritized are surveilled through state accountability, marked as "bad" in the good school/bad school dichotomy, and punished by this portion of the policy that examines them, yet which purports to support and engage them in professional growth. The IL ESSA's ten weighted indicators make heavy use of Foucault's concept of the examination in that the indicators foreground proficiency targets, growth accountability, and data points that unilaterally purport to measure a school's culture or climate and thereafter impose and enforce improvement goals for professional learning activities. The goal of the IL ESSA is not to create a just system, but radically to reform teachers as subjects in ways that ensure their adherence to a normalized set of behaviors that render them under constant surveillance. Unsurprisingly, the state only monitors, surveils, and normalizes those schools it labels as troubled or failing. 
Rather than design and enact a punishment system keyed to specific acts, using the IL ESSA, the state exercises disciplinary power using the disciplining mechanisms to put constant, unseen pressure on teachers to conform to IL ESSA standards and behavioral norms. Additionally, "ISBE will use a system with four tiers...meaningfully [to] differentiate schools" (ESSA, p. 59). The ways IL ESSA indicators and tiers are constructed remake teaching from a highly professionalized, learned occupation into a model in which teachers become workers on a factory floor, deprofessionalizing and infantilizing teachers in a school culture based and focusing entirely on teachers' failure to adhere to the IL ESSA norm. The policy sets up a punitive culture rather than a generative culture in its limitations on the creativity, professionalism, and movement of teachers and students. The

ESSA also requires that ISBE provide this information in an easily accessible and understandable way to parents, caregivers, and community members through the Illinois State Report Card. Thus, in addition to identifying schools for services and meaningfully differentiating schools from one another through a summative designation, ISBE must also provide additional representations of the data for the purposes of identifying subgroup performance within a school and, if applicable, showing equity gaps. (ESSA, p. 60)

In the aforementioned section and throughout the policy, the IL ESSA calls for "meaningful differentiation" of schools that incorporates four labels, including "exemplary," “commendable,” "underperforming,” and "lowest performing.” The "meaningful differentiation” uses the examination as a means to assert state authority over individual educators by measuring teachers' failure to achieve a pre-set standard or norm that imposes a deficit-thinking-based frame, or a damage-centered discourse in which groups are exploited, overly researched and yet 
silenced (Tuck, 2009; Valencia, 2010). The IL ESSA sets forth and describes in detail two levels of schools in need of state-level prescriptive support, labeled as comprehensive schools or targeted schools. The policy labels the lowest-performing schools as comprehensive schools required to receive support, work within a plan driven by expectations and timelines, and perform as approved by the state. While this deficit-based model is intended to direct resources to schools labeled as failing or not meeting expectations, the result is the creation of "a pathologizing approach in which the oppression singularly defines a community” (Tuck, 2009, p. 413). When research or policy centers the attention on pain, damage, and deficits (hooks, 2000), the community is painted in a perpetual self-fulfilling, failing prophecy for generations to come. Labels perpetuate the belief of failure and diminish the hope of success. Deficit discourses sink into individual and collective consciousness. Deficit thinking is highly racialized and steeped in class-based discrimination. Examination can never motivate, only punish, and control. The only thing people in these circumstances can aspire to, according to Foucault's theory, is to oppress and control others by performing the warder's role.

The state's summative designations label schools in ways that not only determine their value, but that mark some schools as valuable or "good" and others as unworthy and "bad." The long-term repercussions of a deficit discourse and viewing schools as broken or damaged position "failing" schools within a cycle of helplessness and powerlessness (Tuck, 2009). This is dangerous to teachers and their schools because it creates a culture of hopelessness and perpetual helplessness and disengagement. Specifically the policy’s summative designation system measures English Language Arts (ELA), Math, and Science proficiency via "all students meeting or exceeding standards on the required applicable assessment” (p. 50). This predetermined norm serves as an apparatus of control but does not account for individual needs, creating and 
reinforcing inequity for those schools upon which the label of falling outside the norm is imposed, since "achieving more equitable social and economic outcomes might require unequal schooling outcomes” (Valli et al., 1997, p. 255). A policy that outlines the same targets in each of ten indicators for all schools does little to address individual differences within and promotes a damage-centered decision-making approach to school improvement in which marginalized groups are over-researched and painted as broken or as failures even in programs designed to help change their circumstances. Using the example of the IL ESSA's predecessor federal policy, NCLB, Tuck (2009) argues that damage-centered research blames poverty, poor health, and illiteracy when describing injury to the community that leaves long-lasting ramifications. The IL ESSA similarly labels schools as under-performing with a damage-centered approach to the school improvement process.

In a damage-centered data collection and analysis approach, the state, acting as warder, constantly surveils and reviews failing schools' data, rendering the school's occupants nothing more than "failing," and discounting entirely the work and worth of its professionals. Performance levels are "described in relative terms of the progress [failing] schools are making toward the identified interim and long-term goals for the individual indicators” (ESSA, p. 69). The detailed analytics are specific, lengthy, and inaccessible to individual educators. As the state exercises its means of correct training in its omnipresent oversight and review of troubled and failing schools' performance, the state alone is secure in the knowledge of what is right as reflected by state standards, creating an air of uncertainty and desperation within failing schools and leading to rampant teacher anxiety. Because detailed analytics are inaccessible to individual educators, IL ESSA indicators subsequently lead not only to uncertainty in professional learning, but also to overly generalized professional learning topics that do not sufficiently address equity 
and inclusion. The IL ESSA is in place to dictate professional learning at a time when it is clear educators need professional learning opportunities that address equity and inclusion (as centered in IL HB 2170) in their school’s specific community context. To wit, in House Bill 105 ILCS 5/22-90, the Illinois General Assembly confirms, "The COVID-19 pandemic has exposed systemic inequities in American society.” It further spotlights how “The negative consequences of the pandemic have [affected] students and communities differently along the lines of race, income, language, and special needs” (HB 2170, p. 28). Now, more than ever, the voices of marginalized groups must be included, but more importantly, centered, and ridded of the damage-centered discourse that, once branded, becomes an inescapable, punitive identity characteristic.

The IL ESSA indicators include detailed analytics with which most educators are not familiar, making identification and enactment of measures more difficult for teachers to relate to, devaluing teachers' role in school improvement based on analytics, and undermines their role as professionals in professional development critical to addressing needs of a diverse student population. State officials, exterior to the organization, conduct the identification process. School educators are therefore not involved or consulted; the process is far from transparent. Schools are assigned point values for each performance level which the policy states are "founded on the principles of transparency, stakeholder engagement, and external validation” (ESSA, p. 69), yet this panoptic evaluation occurs out of view of individual educators.

A result of the failed examination, a system of rewards or demerits are assigned through policy’s labels and subsequent, required participation in the Network. The IL ESSA normalizes and controls educators' movements: educators who are anxious to meet expectations, be taken off of the "bad school” list and receive the state’s superlative label of "commendable” or 
"exemplary." Because the state operates as omnipresent, unseen warder, "invisibility [provokes] a guarantee of order” (Foucault, 1995, p. 200); consequently, their omnipresence ensures the "automatic functioning of [state] power” (Foucault, 1995, p. 201). The policy says, “The LEA will be supported in establishing a strong program monitoring system to ensure that the selected practices are implemented with high levels of fidelity” (ESSA, p. 93), suggesting this monitoring system's decision making is owned by educators rather than state officials. In the state's eyes, educators own the burden of their "failing” school's label but, at the same time, required IL ESSA interventions determined by unknown analytics actually remove all teacher agency and expertise, again, making all-the-less-likely failing schools ever re-emerge as "good” schools. An accountability system such as the one created by the IL ESSA employs disciplinary actions at a micro level in order to remain unseen but to function as an effective tool of control over educators. Educational social reproduction theorists concur with Foucault, theorizing that the dominating class requires and manufactures a perpetual underclass through public education (Bowles \& Gintis, 2011). Based on the way societal inequity is designed into the U.S.' public education system and given the power of the elite, in schools social inequalities are duplicated and replicated rather than rectified in an educational system which places children into the predetermined social order (Bowles \& Gintis, 2011). The IL ESSA policy fails to address social class and racial inequities, including the myth of meritocracy (which promises education will contribute to upward social class mobility for all). Pedagogy, belief systems, and agency of individual educators are called upon for thoughtful consideration in the Illinois legislature's recently passed Culturally Responsive Teaching and Leading Standards for All Illinois Educators (2013). 
While the IL Culturally Responsive Teaching and Leading Standards (2013) call for curricula that honors the lived experiences and backgrounds of all students and families, IL ESSA topics of professional learning provide only generic direction and rely heavily on Network providers to bring expertise and direction to professional learning topics. The IL ESSA's lack of specification creates a likelihood that CRTLS topics will not adequately be addressed and a white-middle-class curricular norm will persist.

Hidden in plain sight within the IL ESSA's language is the message that the state will determine what is "inhibiting improvement" for educators in failing schools because teachers have been marked as incapable. The state employs external surveillance while professional development providers in the state's IL-EMPOWER Network serve as external surveillance throughout the required timeframe. Individual educators' professional expertise is neglected and disregarded in a system reliant upon a Network that serves as external surveillance throughout the required timeframe of a failing school's participation. Individual educators' professional expertise is neglected and disregarded in a system reliant upon a Network that serves as external surveillance and the omnipresent warder, and the state serves simultaneously as expert and enforcer. Such negative consequences of inequities in school cultures subsequently “disproportionately [affect] Black and Brown students,” with disproportionate disciplinary consequences as argued in IL HB 2170 (p. 28).

The IL ESSA never sufficiently addresses the need for a change to an educator's belief system, biases, and subjectivities, particularly those rooted in deficit thinking (Tuck, 2009; Valencia, 2010), in service to the school's community and student makeup (Carter Andrews \& Richmond, 2019). Instead, the IL ESSA focuses on generically addressing teaching performance and adherence to student achievement and growth norms: inappropriate to best practices of 
differentiated instruction. Importantly, educational researchers repeatedly find, "Issues of equity for students and teachers are connected; the more teachers know about their students; needs and possibilities for growth, the more responsive they can be to these needs and possibilities and to providing powerful learning opportunities” (p. 408). As laid out and enforced by the IL Network, generalized and fragmented professional learning topics are insufficient to address failing schools’ equity and inclusion needs (Danielson \& McGreal, 2000; Steen \& Noguera, 2010). Teachers deserve to be empowered to identify the needs of their students and the areas in which professional learning activities may encourage the development of learning opportunities. Deficit thinking, blaming the victim for the failure of a school rather than examining how the school is failing Black and brown students and poor students (Valencia, 2010) disempowers educators. Specifically, the label of "at risk" being assigned to poor students or students of color are known to be inescapable labels, even when used primarily to obtain additional resources. "Damagecentered” (Tuck, 2009) discourse characterizes students of color as broken, marginalized and reduced to culture and history, focusing on minoritized students' failures or underachievement to define the community or describe the needs of the group. Tuck (2009) points to the doll test of the 1940s in which Black children were asked about their impression of Black versus white dolls. Similarly what happens when students and staff are told their school is a poor Black and brown school, the labels a policy such as the IL ESSA places on schools become inescapable.

The IL ESSA monitors schools through an examination that requires submission of quarterly reports and periodic resource reviews. ESSA uses disciplinary power to create a system of punishments and rewards to push educators' behavior toward the norm, which consequentially silences educators in all-important decisions about student outcomes and their own professional learning. These quarterly reports "provide data on progress in achieving identified targets as well 
as utilizing field-based staff who can, if necessary, provide technical assistance and monitor for compliance” (ESSA, p. 92). Field staff, assigned by the state, act as warders, continuously monitoring and observing teachers in underperforming and failing schools. Section 5 includes “computational algorithms" that identify schools in need of targeted support (ESSA, p. 90). These algorithms are used by the warder to control individual educators and their choices of professional learning.

High stakes, sovereign data derived by the state alone also can be revised by the state, giving the warder even more unseen and omnipresent power and control, because revisions to a school's data can be made without educators' awareness. Amendments or revisions to the policy can be made by a Technical Accountability Council, wherein "ISBE will continue to convene a TAC to make amendments as additional data is available” (ESSA, p. 50). In the past, the state employed the TAC to determine expected performance levels and included in the policy that it would again assemble the Council to revisit and redefine expectations throughout the life of the policy. The policy can be changed without individual educators' awareness, which keeps educators in the dark and further deprofessionalizes their work.

While policies by design inherently set parameters and benchmarks, the IL ESSA is unique in its application to prescriptive, state-sanctioned performance improvement of educators, creating inequitable teacher professional development and student outcomes since the diverse professional growth needs of individual educators are disregarded in the improvement system as the policy itself defines success and quality through its set of ten indicators. I argue it is not possible simultaneously to create efficient, docile educators and thoughtful, just educators who differentiate instruction and who follow Illinois’ Culturally Responsive Teaching and Leading 
Standards. As a result, educators' professionalism is ignored and the very policy that sets out to engage and develop educators leaves them vulnerable, undervalued, and demoralized.

\section{The Voice of the Marginalized}

Marginalized groups are a part of society but perpetually on the border of society. When a dominating group speaks for marginalized groups, even with the best intentions, it further marginalizes the marginalized. The IL ESSA policy perpetuates an equity issue in the way it silences the voices of teachers of poor, underresourced, minoritized schools. The policy states, "ISBE will have baseline information on differences, if any, between ineffective and inexperienced teacher[s] who teach at high/low poverty schools and high/low minority schools" (ESSA, p. 99). The policy claims the right to identify and speak for failing schools' disembodied marginalized communities which perpetuates the marginalization because individual voices are not included. "Illinois provides equitable access to a well-rounded education and rigorous coursework in subjects in which female students, minority students, English Learners, children with disabilities, or low-income students are generally underrepresented” (ESSA, p. 106). Rather, an authority or dominating group should allow opportunities for marginalized groups to speak for themselves because their needs and concerns can meaningfully effectuate change and progress. Success only occurs when a marginalized, minoritized group is no longer an object of domination and society as a whole is enriched by those peoples previously rejected as outsiders or outliers.

A strong first step toward accomplishing such an ambitious equity agenda is through the application of standards designed to address equity issues via teacher preparation programs and professional development. Of the institutions Foucault dissects, most are locations in which adults place themselves, willingly or unwillingly, such as prisons, hospitals, and factories. 
Educational institutions, however, are unique in that students are compelled by law to attend. The social institution of school perpetuates social reproduction theory and classifications of students through a self-fulfilling prophecy of applied labels.

Rather than being surveilled, silenced, and punished, people the IL ESSA situates as outliers with minoritized views should have their voices amplified because effective change occurs only once a marginalized group is elevated from its objectification to agency and inclusion in solution-making (Tuck, 2009). The IL Black Caucus took an important step in this process in Spring 2021 with the passing of HB 2170. A policy can amplify, dampen or even mute voices of a particular social class or racial group. The bill proclaims,

Schools identified for comprehensive services will work with pre-approved providers to select the provider(s) that best meet the needs of the school community as determined through a needs assessment/equity audit. Schools will, with their selected provider(s) develop a work plan with improvement targets and metrics related to the information gleaned from the needs assessment/equity audit. (ESSA, p. 13)

The voices of those that are privileged are elevated through the policy's assignment of priority to the "good" school which is typically white and middle-class.

\section{Foucault’s Examination and the Inevitable “Good School/Bad School” Dichotomy}

The IL ESSA establishes a ranking system with punishments and rewards in order to control individual educators. It sets up a hierarchical system used to identify and call out the deviant, or delinquent, as a "failing" school. It creates and maintains a dichotomy between good schools and bad schools, coercing individuals with the potential humiliation of a label of failing. As a result, the policy effectively requires bad schools to exist in order to maintain the 
dichotomy and to feed the school improvement machine. The policy therefore creates and maintains with permanence the category "bad school." Since the IL ESSA remains necessary and valid only when bad schools exist, through this policy the state effectively creates and fuels the "bad-school industrial complex" (Otto, 2021). Without bad schools, rich white schools cannot be labeled "good," comparatively. Furthermore, the good school/bad school dichotomy lacks nuance, establishing or even guaranteeing there will always be failing schools. It also guarantees the bad schools will never leave the list or shed themselves of the "bad school" label.

Good schools are upheld as virtuous in the policy and in society, presumed to have staff and students who work harder, are better, or are doing more thoughtful work than bad schools. The assumption is the good schools have fairly earned their label of superiority as a result of more reflective work and are therefore more deserving of the designation than those labeled as bad schools. That this process is "fair" is reflected in its objective, scientific, data-driven-ness: good schools demonstrate their inherent goodness via objective, easily measurable high-stakes accountability measures. And the numbers do not lie: "bad" schools are bad places behaving badly and in need of correction.

It is no coincidence that the good school/bad school dichotomy is divided along race and social class lines. According to Foucault, a person or group that gets labeled as delinquent becomes viewed as an outsider who can be examined by way of social position and upbringing in order to determine negative antecedents and dispositions. An individual's background is tied to social class. Importantly, the delinquent can be reformed by knowledge imparted by an agency. Viewed as an individual that can be reformed, the delinquent must first have their/her/his background analyzed and studied through the process of the examination. When conducted using policy, social position becomes a root of future failures. 
The creation and cementation of inequities in underserved populations is dangerous because those inequities manufactured by policy illustrate how the IL ESSA has the capacity negatively to influence the very schools it purports to support. Bad schools, or schools primarily made up of low income and Black and brown students, are labeled in ways that uphold and illustrate the idea that "bad school" educators are doing work that is less thoughtful and expert than their peers. They are therefore surveilled and examined regularly by the state in a process designed to identify points of failure and prescribe the path to better learning outcomes through professional development closely surveilled and examined by the state.

The policy's use of the examination provides the state an opportunity to insert its authority and power through regular through a ritual of objectification. Section 4 of the ESSA policy, Accountability, Support and Improvement of Schools, outlines a percentage and the timeline of three years by which individual schools are expected to achieve the pre-established norm, defining the predetermined goals all schools must achieve. However, because high-stakes accountability measures are perceived to be rooted in research and science, their results are assumed to be fair, democratic, objective, and free of bias, resulting in broad acceptance of oppressive systems and procedures. The IL ESSA purports to designate "school quality/school success" when a troubled or failing school can match its list of indicators (ESSA, p. 48).

The IL ESSA labels schools as failing and delinquent for not fitting into the mold of middle-class established norms for school success. But Tuck (2009) connects punitive federal policies like NCLB to damage narratives based on the state's preference of accountability over support, arguing, "I think we can also link research intent on documenting damage to educational policies such as No Child Left Behind” (p. 414). She criticizes NCLB as having been drafted purposefully to identify failures in schools (Tuck, 2009) which draws out the deviant via the 
examination. In this design a policy is set up perpetually to create failures, or bad schools, and therefore keep itself and the state agency, in existence and healthy. For example, such edicts as the "ESSA retains the NCLB requirement for annual testing, and states now have additional say in selecting non-academic indicators and determining what weight both academic and nonacademic indicators will hold within an accountability system” (p. 14). Indicators are identified in the IL ESSA, but the policy also states that indicators can be changed by the state agency at any time. Non-academic indicators include the voices of marginalized groups-groups overrepresented in troubled and failing schools_-and places punishments and sanctions on those schools unfortunate enough to earn the label "failing."

When schools fail to meet the state’s norms, they also face the punitive requirement to enter the IL-EMPOWER Network. Thus, the IL ESSA is constructed in ways designed to control educator learning and behavior through its power of normalizing judgment. The IL ESSA examines, analyzes, and prescribes the ways each educator should be improved; as Foucault reveals, behavior that does not meet the rule departs from the norm. The IL ESSA thereby is used to point to failure to reach prescribed standards and labels schools as deviants to be corrected based on the IL ESSA's prescribed set of state standards in order to reform failing schools. One consequence of this examination is a lack of attention to critical matters of individual needs and disengagement in the professional learning process.

Through the IL ESSA, the state professes to offer non-punitive support, but a punitive message is sent by the labeling of schools as low quality or failing; these schools are unable to exit until a list of criteria are met, as elusive as the expectation sounds. In this way the policy purports to "cure” failing schools through judgment of the anonymous, ominous normalizing gaze, expecting individuals to conform to a specific standard. A school's conformity may then be 
rewarded, by which the IL ESSA attempts to create absolute homogeneity while it hierarchizes in comparison to the norm and objectifies schools. "Those schools that receive targeted services but that are unable to increase academic achievement/growth within a four-year period of time would then be identified as a chronically underperforming subgroup and required to receive comprehensive services” (p. 59). ESSA language outlines how educators are "supported in establishing a strong program monitoring system to ensure that the selected practices are implemented with high levels of fidelity" (ESSA, p. 93), yet the policy dictates that, by being “supported,” educators are surveilled which significantly reduces teacher autonomy, professionalization, and decision making. Through the policy's use of the examination, hierarchical observation, and normalizing judgment, the IL ESSA's outcomes surveil and create records of surveillance. The IL ESSA thereby turns the Network's examination of teachers into a Foucauldian "case" to be scrutinized and studied through an invisible exercise of power. This pathologized "case" carries the demand for "cure" but never delivers. The outcome is a system that attempts to reform schools labeled bad, sending the message that failing schools need to be fixed or cured, that failing schools' educators are to blame, and failure can only be fixed by the state rather than the individual educators themselves.

In this scenario, individual educators are cast as subjects whose only task is to meet a specific norm as outlined by the IL ESSA and, if they cannot, educators are subsequently labeled “not effective.” Norms are established, surveilled, and enforced by the state. Educators are viewed as subjects and any abnormality is punished, not in a manner of the body, but of the soul. Opposed to the imprisonment or physical torture of the outside of the body, the inside of the body, or the heart, will, and mind, are the foci of imprisonment. Failing educators' bodies are not imprisoned as a punishment, but their souls are observed, controlled, and supervised in a highly 
ritualized manner that includes the submission of teacher performance data. Power is "exercised on those punished-and, in a more general way, on those one supervises, trains and corrects, over madmen, children at home and at school, the colonized, over those who are stuck at a machine and supervised for the rest of their lives” (Foucault, 1995, p. 29). The supervision is routinely automated. Because schools as social organizations follow and resemble a factory or a military model where no one is individualized, the "bad school industrial complex" (Otto, 2021) continues on its own volition, even when the operator of the machinery or the warder is removed (Foucault, 1995). In this way schools mirror factories, in a production that includes a bossworker model (Bowles \& Gintis, 2011) and designed not for educational transformation, but for social class reproduction.

The label "failing” creates a shameful spectacle to be publicly viewed, as the classifications are on display through media. According to Foucault (1995), the purpose of the spectacle is to exercise power on those who view it. The very public discipline exercised by the state through the IL ESSA has gone from a mere spectacle to an instrument of power and control over individual educators. The spectacle of failure is also made available on the state's websites, marking a school as bad, enacting a public shaming, and having emotional and economic consequences for the failing school's community. And, not to be forgotten, modern power is productive power in the formation of knowledge through control of the mind, will, and soul (Foucault, 1995). Through the IL ESSA, and in a technique of modern power, individuals are judged for and marked by what they fail to do, standards they fail to achieve by their failure to respond to the state's normalizing judgment. Foucault theorizes that the modern-day punishment of the soul, as opposed to punishing the body, makes it easier for delinquents to be surveilled, analyzed, and controlled, but also to become tools of the state and those who "take the fall” for 
the dominating class' crimes. In this way the good school/bad school dichotomy plays out in the elevation of white, middle-class schools over poorly resourced schools attended by the poor, immigrants, and students of color. The cost of the state's objectification of failing schools is the perpetuation of delinquency (Foucault, 1995) through punitive labels, making the individual believe in this inescapable label that is placed upon them, similarly to the inescapable label of "at risk” of educational failure (Strong, 1998; Tauber, 1998; Chandrasegaran \& Padmakumari, 2018).

Since, according to Foucault, the dominating group has an interest in perpetuating teacher delinquency as the subject of its examination, individual educators are purposefully objectified and labeled, punished at the level of their soul by being made to feel hopeless and dominated. Since "Delinquents are not really delinquents, rather they are victims of oppression" (McWhorter, 1994, p. 36), schools and educators labeled as “failures” fall victim to being branded as such and are controlled, marked, managed, and subsequently perpetuated as delinquent resulting in an educational self-fulfilling prophecy.

An attribution of poverty therefore naturally reproduces inequity by design. Once poor and under-resourced schools are labeled as troubled or failing the cycle is doomed to repeat for generations. Rather than the myth of meritocracy or the Eugenicist-inspired "scientific" belief that an IQ score will determine one's level of educational attainment (Valencia, 2010), the social class of one's family is most responsible in influencing one's length of involvement in formal education and subsequent lifetime earned income (Bowles \& Gintis, 2011; Rivera, 2015). In this way the state's punishment of the failing teacher's soul effectively controls, but not in a manner meant to improve a school or student outcomes, but rather to maintain a failing school's "place” in the good school/bad school dichotomy and to keep the machine of "the bad school industrial 
complex” (Otto, 2021) generating customers. The IL ESSA's “failure/bad school” label and the state's resulting deprofessionalization of failing schools' educators imprisons and punishes the souls of educators and the public display of labels seeds fear and insecurity in even those schools not currently categorized as failing because the ESSA's manufactured fear of repercussion looms large: as specter and spectacle.

The state's examination objectifies the process of student achievement and educators' professional learning by tracking performance and comparing it to other schools and educators in ways that reduce teachers and students to nothing more than objects analyzed against the statesanctioned norm. The IL ESSA defines acceptable performance levels and subsequently punitively requires the use of the IL-EMPOWER Network to enact professional improvement activities upon individual educators. The examination and surveillance of failing schools includes regular observation through "submitted data on teacher effectiveness" (p. 103). The omnipresent visibility of educators as subjects assures disciplinary power in a "spectacle of power” (Foucault, p. 188) reinforced via media channels. The state captures data and documentation in an attempt to "fix" or "cure" failing schools. By these means educators become objects: describable, analyzable objects judged, measured, and compared.

The IL ESSA's required data collection ranks schools and enacts normalizing judgment as a powerful means to create docile bodies of educators. Through normalizing judgment, standards and ranks encourage docile bodies rather than innovative educators because educators never reach the pinnacle, are never enough, since there is always another level above, another level to be achieved. The state's disciplinary actions are enacted through minor humiliation and micro-penalties which sanction labels of failure and requirements to have professional development conducted through the Network when teacher behavior falls outside the norm or 
expected standard. Specifically, the policy defines teachers who receive a "needs improvement" or "unsatisfactory” designation on their evaluation as "Ineffective Teachers” (ESSA, p. 101). The level of humiliation that occurs when specifically labeling a professional educator “ineffective” is detrimental to or can derail entirely teachers’ professional learning processes. Furthermore, labeling schools as "failing” places the humiliation on the entire school in characterizations such as:

Schools identified for support that do not meet the state-determined exit criteria will be supported in selecting contextually appropriate, evidence-based practices that have more rigorous levels of evidence supporting their effectiveness. The LEA will be supported in establishing a strong program monitoring system to ensure that the selected practices are implemented with high levels of fidelity. (ESSA, p. 93)

Network exit criteria serve as yet another Foucauldian examination in that criteria are in no way pedagogical or didactic but meant merely to elevate a few and pathologize the many, reifying structural organizational inequities and perpetuating the inequitable and deficit-based "good school/bad school” dichotomy for which the IL-EMPOWER Network has failed to yield a “cure.” Specifically, the IL ESSA outlines exit criteria by which a school will be judged no longer to be required to participate in the IL-EMPOWER Network. The policy's exit criteria include that "a school no longer meets the eligibility criteria for comprehensive support and improvement" and has "established a growth trajectory for students, including those at the highest and lowest levels of attainment” (ESSA, p. 87).

The Network’s failing school exit criteria relies upon student performance data from “objective” high-stakes accountability instruments the policy labels as "school quality indicators”. It says, “The weighting of the academic indicators and school quality indicators will 
identify schools in need of support and as well those well positioned to support them” (ESSA, p. 15). Not only does this send a message to educators that test scores solely determine school quality, but it also cements the long-held misconception that the test scores equate to upward social class mobility. Test scores are not an effective predictor of upward mobility (Attewell, 2009; Destin, 2020; Petrilli \& Wright, 2020). "Educational tracking based on competitive grading and objective test scores is only tangentially related to social efficiency” (Bowles \& Gintis, p. 103). However high-stakes test scores do serve to perpetuate the factory model of constant supervision and machine-like operation.

Foucault theorizes the primary purpose of disciplinary power is to train individuals to be controlled and to conform to the norm by way of an omnipresent surveillance that creates docile bodies. The need to be inclusive and attentive to individual needs of learners and educators should drive the improvement process and selection of professional development topics. However, doing so in a system established to control and create conformity does not allow individuals' professional learning needs to be prioritized in the selection of activities. Section 5 of the policy, Supporting Excellent Educators, identifies the need for comprehensive and targeted services in the areas of "governance and management, curriculum and instruction, climate and culture” (ESSA, p. 93). It calls for an assessment audit that targets areas of improvement and assigns an IL-EMPOWER Network provider to the school. The factory model's attempt to address professional learning needs is efficient only for creating docile bodies and falls short in making substantial changes to teacher efficacy.

The IL ESSA is designed to create docile bodies of students and teachers alike that are desirable as expedient and obedient for efficient and timely compliance to the policy. The policy deems the schools will be notified that they are "required to partner with an IL-EMPOWER 
Network Partner Provider(s) for comprehensive improvement. Furthermore, "Schools will be identified using data from the full range of the accountability system” (ESSA, p. 83). "Most simply, the IL-EMPOWER Network will serve as the statewide system of support for schools identified for comprehensive supports and services” (ESSA, p. 13). The IL ESSA policy defines professional learning needs and points guidance to the IL-EMPOWER Network of pre-approved professional development providers in which individuals not only are required to police themselves, but also one another, upholding what the state establishes as "good" levels of achievement in order to create docile bodies of teachers in the underperforming schools for the purpose of the creation of efficient workers. This policy language in Section 4.2, entitled Identification of Schools, closes the door on the important focus on equity and inclusion by identifying schools for comprehensive services and requiring the use of a needs assessment/equity audit that blanketly cede learning needs to an organization with the requirement that they must work only with approved providers.

\section{Omnipresent Oversight of State Agency Officials}

Individual educators do not need to be able to see the IL ESSA policy authors or government officials in order to be controlled by them due to the establishment of its hierarchical punitive system of judgment and correction for those who do not meet the standard. The mere acceptance of an omnipresent system of surveillance creates normalized behaviors among individuals who adhere to expected norms (Foucault, 1995). As a consequence of not meeting expectations, schools are “...required to partner with an IL-EMPOWER [Network] Partner Provider(s) for comprehensive supports and services in developing and implementing comprehensive improvement plans...” (ESSA, p. 87). Individual educators' knowledge or desires are not parts of the selection of professional development topics; therefore, power is 
applied through normalizing judgment to the failing school. The cost of the absence of educator input is the disengagement of the very educators the policy purports to engage.

Unseen, omnipresent state education officials function as warders, in possession of sovereign knowledge as power while physically not present in the school, who surveil the work of individual educators as the Network makes a single observance meant to surveil and assess a school's inner functioning via the disciplining mechanisms without regard for individual differences in improvement needs for educators who serve a diverse group of students.

\section{The IL-EMPOWER Network as Gobelin}

If the primary purpose of disciplinary power is to train and control individuals (Foucault, 1995), the IL ESSA policy exchanges creative and independent professional learners for efficiency and docile learners who are held to a prescriptive set of learning objectives and topics outlined by officials of the state. Much like the Foucault illustration of $17^{\text {th }}$ century Gobelin, a factory/school that organizes, trains and certifies apprentices, the IL-EMPOWER Network is mandated to organize, train and certify teachers it labels as "ineffective" via a surveillancefocused master/apprentice model. In both the Gobelin and the Network, record-keeping and secreted review of data by the master, or the agency-approved Network providers, are key to the examination and responsible for the certification of success.

Professional learning objectives should be outlined based on the individual needs of educators, rather than being prescribed by the state (Fallon \& Barnett, 2009a; Ricken, 2011). The Accountability section of the IL ESSA is designed to make use of individual educators' selfgovernance through its establishment of standards by which individual schools measure their progress and achievement. However, the policy assigns Network providers and School Support Managers to each targeted or comprehensive school to provide guidance and technical 
assistance, which creates a set of learning priorities designed to meet the needs of the state rather than individual educators. This apprentice/master model of power creates carefully prescribed movement and coordination of forces wherein the force of a larger machine is utilized to divide the failing school into individual members who are surveilled and then provided individual activities. The Gobelin model uses a timetable—one of the three Foucauldian disciplinary mechanisms - that breaks down time for professional learning in order to capitalize every moment during training, the results of which are subjected to the state's examination. Precise, unseen record-keeping is used to determine which schools will be allowed to advance out of the label “failing," and exit the Network’s surveillance and punitive appraisal. As Foucault (1995) theorizes, time ultimately holds the power to control the body in ways that break down individualism and manufacture docile bodies. From my experience as superintendent of schools I am confident that good and thoughtful teachers are not docile. Highly effective teachers are inquisitive risk-takers who challenge students and one another to seek new ideas through critical thinking. The cost of creating or maintaining docility in teachers is the loss of creativity and the power to challenge a teacher's comfort zone, which ultimately thwarts new ideas and their expression in the learning process. Docile-bodied teachers in low-income schools are even less effective. Much like the Gobelin school that capitalizes on the use of time and mechanizes instruction (Foucault, 1995) working-class schools offer students little choice or autonomy, rote directives, and low levels of rigor (Anyon, 2011). In fact, even stellar teachers have been documented to dumb down and mechanize curriculum and instruction for their low-income students (Finn, 2009).

The IL ESSA sets out to divide, organize, and evaluate educators, since "ISBE will monitor the school's performance plans to ensure that they are on track to meet improvement 
targets or, if a school is not meeting performance targets, assist in amending improvement plans to focus specifically on areas inhibiting improvement” (ESSA, p. 91). The IL ESSA's discourse intimates a school and, by association, the school's leadership and teaching staff, will be monitored and micromanaged by the state. This micromanaging of the educational Gobelin mandates the waste of time as forbidden: "ISBE will monitor the school's improvement plans to ensure that they are on track to meet improvement targets or, if a school is not meeting performance targets, assist in amending improvement plans to focus specifically on areas inhibiting improvement” (ESSA, p. 95). Creativity, individuality, and attention to the individual needs of educators are thereby exchanged for conformity, adherence to normalizing judgment, and the creation and maintenance of docile bodies.

The IL ESSA resembles a Gobelin model in the way it smothers pedagogical practice with practices of disciplinary time and segmentation in a factory/school model. Division of time and certification of progress is therefore embedded into professional learning. In order to divide and examine, the IL ESSA calls into focus the use of a data collection and reporting tool called Ed360. The Ed360 dashboard is populated with school performance data and available to the public, stating that "ISBE will monitor progress through the submission of quarterly reports that provide data on progress in achieving identified targets as well as utilizing field-based staff who can, if necessary, provide technical assistance and monitor for compliance” (ESSA, p. 99). This prescriptive approach examines and controls bodies but goes against the need for educators to be offered choice and flexibility in the process of meeting individual learning goals in order to be engaged (Lieberman, 1995). This state mandate is problematic because the loss of professional autonomy deprofessionalizes educators (Frostenson, 2015). “Teachers simply lose the power to influence their work, becoming prey to malicious management ideologies, political reforms, 
pedagogical experiments, incompetence of municipal and private education organizers and so on” (Frostenson, 2015, p. 22).

In a teacher/apprentice model, Gobelin school training is kept separate for those with experience compared to those undertaking a novice apprenticeship (Foucault, 1995). Similarly, the IL-EMPOWER Network divides training based on an audit of needs in the areas of “Governance and Management, Curriculum and Instruction and Climate and Culture” (ESSA, p. 95). Foucauldian division of training is presented as part of the IL ESSA model, differentiated by the bad school/good school dichotomy or the apprentice/master of a Gobelin school. In this organization of geneses (Foucault, 1995), the IL ESSA also is designed to divide teachers using the labels ineffective, out-of-field, and inexperienced. Foucault (1995) uses the term "organization of geneses" to explain the process of human development in which a schedule is used to make an individual more useful, controlled, and efficient. In schools, dividing an individual teacher's time allotted for professional learning into segments or parts that can be administered in a successive order creates productive development that can be more easily surveilled and analyzed. This process allows each segment to be examined after completion when rank or label is pronounced on an individual. The IL ESSA policy organizes professional learning into segments through the IL-EMPOWER Network and the Network’s providers who are bestowed upon the rank of "approved provider" due to their association with the rank/label of "good school" by the state. According to the state, good schools are positioned in the IL ESSA hierarchy as having reached a highly capable stage of authority over teachers ranked as "failing." Repeated throughout the IL ESSA are statements regarding the need for schools to be supported by those better positioned to do so, such as, "This statewide system of support in connection with the accountability system assists not only in the identification of districts eligible to receive 
supports but those who are in a position to provide support, should they choose” (ESSA, p. 17). The IL ESSA’s assertion that some schools are better positioned to support peer schools transmits to the individual school and educators that they are not positioned or capable of determining the focus of professional learning needs and therefore in need of a master in the master/apprentice model similar to the Gobelin school. Promoting school personnel whom the state deems "good" to oversee and direct schools labeled "bad" pathologizes without hope of cure.

The IL ESSA specifically calls out a need to avoid "sit and get” models of professional learning (ESSA, p. 92) that feature an efficient timetable and do not waste time (Foucault, 1995), but the "sit and get” are ineffective adult learning models (Bill \& Melinda Gates Foundation, 2014; Calvert, 2016, Carter Andrews, 2019). Division of teachers’ time and creation of docile bodies, like in a Gobelin school model, dilutes adult learning through rote exercises of professional training meant to normalize. These rote activities deprofessionalize educators yet are paradoxically referred to by the state as “professional training," "professional learning,” or “professional development.” As an example, the IL ESSA policy specifically calls attention to its support for an online professional development site called Online Impact. The Online Impact program provides fifteen online professional development workshops. The courses are asynchronous, "sit and get” sessions and are billed by designers as being available for K-12 educators in a timeframe most convenient for them. As a disciplinary mechanism, time is capitalized and broken into segments in professional learning such as the Online Impact program. Not only does the Online Impact program divide space and time for professional learning, it also creates a figurative panopticon with disciplinary mechanism as the tool used to surveil the sessions in which educators participate. 
The "seriation" of successive activities makes possible a whole investment of duration by power: the possibility of a detailed control and a regular intervention (of differentiation, correction, punishment, elimination) in each moment of time; the possibility of characterizing, and therefore of using individuals according to the level in the series that they are moving through; the possibility of accumulating time and activity, of rediscovering them, totalized and useable in a final result, which is the ultimate capacity of an individual. (Foucault, 1995, p. 160)

Regular intervention that includes correction and punishment in a policy regulated by those deemed capable of certification establishes a factory model of learning. But this factory model, focused on efficiency and docility, ignores the needs of individuals who are most in need of thoughtful, reflective professional learning and support.

Equity and docile bodies are made mutually exclusive in IL schools governed by the IL ESSA section on Technical Assistance Regarding Evidence-Based Interventions in that the primary purpose of disciplinary power is revealed as necessary to train individuals to state control and to exercise normalizing judgment in order to produce subjects who conform to the norm. This insight is not hidden away, rather exists in plain sight as the IL ESSA policy states, "The intersections of IL-EMPOWER, accountability, and assessments are really the heart, head, and hands of the plan” (ESSA, p. 14). This move lends human characteristics to the machinery of omnipresent surveillance by the state, all the while stripping teachers of their humanity in the policy's deployment. An accountability such as this creates an even larger equity problem for poor schools or those who are home to historically marginalized students, as their educators are expected to "improve" via the same professional learning activities of schools with great wealth of resources. These represent internalized expectations imposed on teachers by someone in a 
position of power, similar to a figurative panopticon in which the omnipresent surveillance of the figurative panopticon thwarts creative lesson planning and thoughtful professional learning, so those who suffer most are those students already underserved. Their classrooms are centered on low-level directives compared to their peers in affluent schools whose classrooms are rich with rigor and student engagement (Anyon, 2011). This examination sets students up for social class reproduction rather than upward social class mobility.

Schools identified for comprehensive services will work with pre-approved providers to select the provider(s) that best meet the needs of the school community as determined through a needs assessment/equity audit. Schools will, with their selected provider(s) develop a work plan with improvement targets and metrics related to the information gleaned from the needs assessment/equity audit. (ESSA, p. 13)

The comprehensive services directed and orchestrated by assigned providers creates docility in the very teachers the IL ESSA purports to engage in professional learning. In the figurative Gobelin school of the IL ESSA, the apprentice-like failing school deemed in need of training is made to pay the agency's approved providers at a preestablished state-set rate for training and then subjected to recording of data used as examination. Federal funds are sent to failing schools, only to then be redirected to the "good schools" by the state by way of payment for Network services and trainings. This practice perpetuates the label of failure and fattens Network providers' pockets as "good schools” are left free to use state funds at their discretion without any of the IL ESSA oversight placed on troubled or failing schools. The overt message sent to all Illinois schools and to the public is underresourced schools that serve Black and brown children, low-income children, and immigrant children do not have the professional expertise or 
knowledge to teach their communities' children or to choose the best professional learning for their building.

\section{Autonomy Must Be Bestowed upon You, Docile Bodies}

In its factory/school Gobelin model, the IL-EMPOWER Network establishes external experts as masters who impart wisdom upon the teachers of "bad schools" as if they are apprentice level, regardless of the years of experience, professional endorsements, or curricular expertise each may have. The IL ESSA labels schools with a majority of low-income students and families as "bad schools," their teachers as "ineffective," and assigns oversight by approved external providers who often are teachers of students in affluent schools. The IL ESSA is designed explicitly with the assumption that teachers at affluent schools possess far deeper understanding of effective methods of instruction and school improvement, not simply that their students are better educated in test-taking. This assumption infers educators at lowsocioeconomic-status schools or schools in which predominantly Black and brown students attend are not deserving of professional autonomy without having that autonomy bestowed upon them by the sovereign.

On its surface the IL ESSA appears not only to seek input from educators, but to be fairly focused on equity of resources. It says, "Upon notification from ISBE will begin completing a needs assessment/equity audit” (ESSA, p. 91) on individual schools. At the same time, the IL ESSA prescribes the steps by which the input will be received and considered. "ISBE will monitor the school's improvement plans to ensure that they are on track to meet improvement targets or, if a school is not meeting performance targets, assist in amending improvement plans to focus specifically on areas inhibiting improvement” (ESSA, p. 91). Thus the IL ESSA requires the use of approved external providers who come from schools labeled "exemplary" based on 
student achievement on “objective” high-stakes accountability measures. This polarity sends the message that teachers are not in control or seen as professionals, rather they can only be granted autonomy (Frostenson, 2015) by the state. Autonomy must be bestowed upon them by those in positions of power, such as state agency officials. Educators and the general public are made to believe the state is the only entity worthy or capable of such authorization. This weakens the general perception of public educators in addition to devaluing their human and professional worth.

After working with the Network’s approved provider, the policy outlines how teachers in troubled and failing schools are expected to make improvement or be subjected to additional punitive action, much like a figurative panopticon. It directs, "Schools that are not making reasonable progress will work directly with ISBE to determine additional interventions” (ESSA, p. 100). The labels persist and push teachers farther away from creative engagement in new ideas, sending a message that failing schools are "trainable” to become more like their affluent peers, if only the failing school's staff will adhere to the state's prescription of professional development via Network professionals. Ultimately, though, it is only the state, through its ISBE-approved Network that is capable of orchestrating and evaluating a failing school's progress.

\section{Conclusion}

The myth of meritocracy provides a false sense of hope in the upward mobility of social class as a result of hard work, effort, and education. "Meritocracy does not challenge social class; it simply gives affluent classes cover. They can blame the poor and working class for their apparent failure and congratulate themselves for their victory in a 'fair contest” (Finn, 2009, p. 167). In creating the IL ESSA, the state simulteneously creates mechanisms that fuel the myth of 
meritocracy and the good school/bad school dichotomy. The state establishes a contest between schools with a system it refers to as accountability, but a system that labels schools and places them in contest with one another. The system then enforces punishment and creates docile bodies by requiring failing schools pay other schools to consult them and "train" them.

A system of surveillance is established as a disciplining mechanism, but more concerning are the ways the policy sets out to punish. The spectacle (Foucault, 1995) is enacted on troubled and failing schools because what is happening is not pedagogical, it is punishment. Labels of “failing” and requirements to enter a Network with exit criteria stipulate and fuel the good school/bad school dichotomy. Such labeling signifies the breaking of a school's soul—and thereby the community's soul—and the souls of individual educators in a public display of a spectacle of punishment. Foucault (1995) aligns this form of normalizing judgment with torture, a spectacle intended to send a message of punishment to those watching.

Schools labeled by the IL ESSA policy as "bad schools" are nearly universally lowincome schools purported to have low expectations for students and teachers who bark at them, which then results in a lack of student engagement (Anyon, 2011). When the IL ESSA then creates docile teachers who are not provided agency in their own professional learning, the system that appears to be intended to improve "bad schools" actually reproduces, maintains and even exacerbates the dichotomy by eliminating the creativity and thoughtfulness of teachers in exchange for broken spirits. The cycle is then repeated, and the system fails its students. 


\section{CHAPTER V: FINDINGS AND RECOMMENDATIONS}

The IL ESSA policy was drafted and enacted by Illinois State Board of Education (ISBE) in response to federal ESSA legislation that directs measurement of school performance and mandates improvement. Specifically designed with the intent to improve the ways in which instruction is delivered, the IL ESSA establishes the IL-EMPOWER Network for professional learning. The policy commands authority not only in the topics of professional learning but also in the process and identification of expert partners from which failing schools must select and pay for professional development consultation. In Illinois schools, the professional development process is micromanaged by the IL ESSA; teacher input is discounted and disregarded, creating docile bodies and disengaging teachers as learners. Teacher docility is created and maintained through at least three Foucauldian practices: hierarchical observation, normalizing judgment, and the examination. The IL ESSA mandates disciplinary techniques to control the individual teacher in an efficient and effective manner because the specific process of improvement is defined and micromanaged with a school's poor performance as grounds for the state to administer not only the examination, but the “cure.” There are, however, significant implications and consequences of this type of state control in the larger context of teachers’ professional learning and established best practices.

\section{Research Findings}

I have employed Foucault's theoretical concepts of surveillance, observation, normalizing judgment, and the examination, among others, as a collective lens through which to analyze the IL ESSA policy. This legislated policy significantly influences the way schools spend professional learning time and oftentimes meager financial resources for activities, in that it requires failing schools to resolve issues of ineffective teachers or underperforming schools 
through mandated data collection, labeling systems, and assignment to the IL-EMPOWER Network which surveils, examines, and prescribes judgment on failing schools’ faculty. Undergirded by the persistent myth of educational meritocracy, the IL ESSA plan purports to lift those schools its standards label as "failing." The IL ESSA establishes the mandate that Illinois’ failing schools are required to rely on good schools’ staff for professional development and must pay them for this privilege: for good schools’ staff's support, consultation, and surveillance. In reality, by naming some underresourced schools as "bad schools,” the ESSA does little to nothing for those underresourced, underrated schools; rather, those bad, failing schools are employed to pronounce and enact normalizing judgment that serves to make Illinois' "good schools” not only feel winning or superior, but to anoint "good schools"” staff as warders of "bad schools": punitive labels and treatment not designed to improve failing schools, but to lift good schools into a savior position in ways that make it seem as if good schools have justly earned their goodness. Consequently, the message sent to educators and the public is that failing schools’ staff are incapable of monitoring their own performance and projecting their own learning goals, and that they must rely on better-labeled schools’ staff to learn how effectively to teach. The implication is that teachers in failing schools are poor pedagogues, not knowledgeable, unwilling, and unable to utilize the resources they have been generously given by the state. As a result, failing schools’ teachers are humiliated, deprofessionalized, and become disengaged from their own professional learning processes. Indeed, a Gobelin factory-style system is established and enacted on failing schools: a mechanized model that effectively dumbs-down professional development and teacher expertise rather than enacting a respectful, guild-like system of professional development, and that 
punishes the souls of failing school staff by monitoring and surveilling teachers' use of time, space, and movement.

\section{The IL ESSA's Creation of a "Fair Contest"}

The IL ESSA creates so-called objective labels for teachers and for schools, establishing and upholding a hierarchy on the performance of schools, teachers, and students and using that hierarchy to determine which schools will be humiliated publicly and receive sanctions. Schools are placed in contest with each other as only ten percent are permitted by state policy to achieve the highest mark and label of "exemplary.” Those who lose the contest receive sanctions and required participation in the IL-EMPOWER Network for professional development.

Perhaps the most significant reason state-imposed limitations on school success are so frustrating and punitive is that while the IL-EMPOWER Network provides an opportunity for educators to learn from peers, it falls far short of best practice since effective learning must be conducted over time in order to build and be successful, not lost through processes of learning “fossilization.” Psychologist Lev Vygotsky (1978) theorizes fossilization as the process by which new knowledge is lost when connections to the concept are not solidified over time. For this reason, it is essential professional development efforts be intensive and sustained over time in order to have an impact (Garet, Porter, Desimore, Birman, \& Yoon, 2001). Indeed, professional development is most effective when schools are provided the tools to offer professional development internally so that professional learning is job-embedded, intensive, sustained over time, and tailored to individual school and teacher needs. The IL-EMPOWER Network cannot provide this in its role as an outside warder of the state established solely to surveil and label schools because it operates as a panoptic outsider rather than a trusted partner with established personal relationships (Hargreaves \& Fullan, 2012) in schools. 
The IL-EMPOWER Network builds a Gobelin school factory model when a guild-based model should be built. When the factory model of a Gobelin school creates docile bodies, that docility comes at a price: loss of creativity and innovation. In contrast to the Gobelin school model of a factory where professional learning is regulated by time and divided by task completion, a guild- based model allows teachers to be curators and creators of their professional learning design. Rather than a sovereign dictation of activities that are required to be completed in order to receive certification to be released from the state’s hold of the Gobelin-like Network, educators can instead be acknowledged as and treated as artisans and people of extensive expertise who envision, design, and construct their learning paths with creativity and innovation in collaboration with peers. A far better model than the Goeblin model is a guild-based model of professional learning that allows for strong engagement as theorized in Vygotsky’s (1978) model on the zone of proximal development (ZPD). Vygotsky (1978) defines his zone of proximal development as learning stimulated through the learner's interactions with others, or between two or more people in a co-construction of knowledge and understanding (Vygotsky, 1978). When exploring Vygotsky’s theory, Wertsch (as cited in Goldstein, 1999) explains how, when a learner operates within the ZPD, “'the mind extends beyond the skin’ into a socially shared space” (p. 649). Specifically, the ZPD is the space between the independent learner’s instructional level and the level at which the learner can study with a teacher or more proficient peers (Goldstein, 1999), making the ZPD a “site for the co-construction of knowledge” (Goldstein, 1999, p. 650). Through utilization of the ZPD, the learning process paves the way for independent developmental progress (Vygotsky, 1978).

A factory production system will never "train” teachers in ways that enable all kids to learn, particularly if the state continues to rely on white, middle-class schools' "good" teachers to 
normalize and correct "failing" teachers. What this process amounts to is a kind of colonization of bad schools by good schools' staff. This form of colonization valorizes educators in the "good schools" and enacts a colonization of "bad schools," many if not most of which are underresourced schools within communities made up predominantly of people of color, immigrants, and the poor, where white, middle-class values are mandated and imposed on failing schools as expectation, standard, and cure. Such colonization of underresourced schools relies upon what Eve Tuck (2009) theorizes as a damage-centered approach, wherein harm and injury are made to result from opposing an oppressive, dominating view on a community's existing well-formed and enacted value system.

Expecting the teachers of "good schools" to be able to "fix" the "poor kids" is a deficitbased, racist, classist notion that silences voices of educators who can best support failing schools but, more concerningly, this expectation irreparably injures those schools the state labels as "failure” and “damaged.” In order to meet students where they are, and create engaging lessons based on students' knowledges, teachers have to come to operate from a strengths-based (Yosso, 2005), anti-deficit approach (Valencia, 2010) to show students their and their families' worlds outside the classroom are valued and thoughtfully, meaningfully incorporated in learning (Emdin, 2016). Like Tuck, Emdin theorizes urban youth in traditional public-school classrooms as neo-indigenous because of the ways they and their communities are made to suffer from colonization. By way of solution, he proposes a democratic "reality pedagogy" focused on meeting a student on "his or her own cultural turf” (p. 27). Tuck and Emdin both argue a failure to embrace students' lives outside of school is more than ineffective, rather is damaging. I align my thinking with Tuck's (2009) in that she insists researching "failing” schools so findings can be used to advocate for additional resources results not in lifting the community, but in re- 
colonizing communities while damning failing schools to the fate of being permanently labeled as damaged, lacking, and its students as savage. When professional learning is provided by white, middle-class educators labeled by the state as "successful" and based on the ability of their communities’ students conforming to the state’s norm, the learning they might offer teachers in failing schools does not value or out-and-out devalues neo-indigenous students’ cultures. In this way, the IL ESSA privileges and amplifies the voices of "good schools" and provides optics for the public that the state is attempting to "fix the poor kids" (Emdin, 2016).

\section{Perpetuating School Failure}

The American Dream began as a colonial enterprise of frontier (de Tocqueville, 1945). It has evolved to become a promise to those willing to work hard enough: the opportunity to become anything they desire. Coupled with the myth of meritocracy that falsely assumes a capitalist society allows for upward prosperity and social mobility (Markovits, 2020) and compulsory public-school attendance, this educational myth sends the message that, since the state provides every child the tools to get a free, public education, every child is then eligible to fulfill the American Dream, but only so long as the individual child is willing to make the effort to learn. The danger of this narrative is that it hides class stratification within schools where students in the failing schools, of lower social classes, receive instruction designed around rote learning activities that encourage their docile, passive engagement while schools of affluent communities are designed to engender creativity, freedom of movement, and thoughtful engagement in lessons (Finn, 2009) in schools designed to reflect the hierarchy of the workforce (Bowles \& Gintis, 2011). Failing schools are blamed and their failures are made a public spectacle using "objective" labels that failing schools only rarely escape—having one success story every once in a long while reinforces the badness of bad schools while giving just enough 
hope for a turn-around to the public and failing schools to keep the myth alive and thriving. State and public blame are used to dismiss the kinds of educational inequities policies such as the IL ESSA introduce and uphold. Consequently, the American Dream and the myth of educational meritocracy are revealed as anything but aspirational, rather simply as mythic evidence and perennial reminder that educational "success" is a category reserved for only the extraordinary top 10 percent. Far from the promise of a level playing field where everyone can reach the gold ring, these myths are opaque enough so that they neatly cover the truth of social reproduction theory and panoptic omnipresent state shrouded in an "everyday man” success myth very few achieve, by design. It is little wonder that failing schools habitually remain on the "failing schools" list.

Case in point, policies such as the IL ESSA promise to make sweeping improvements to progressive education given the state's sovereign position and authority to label "goodness," the likes of which translate to economic boon for those in communities lucky enough to support "good schools." Those schools that "earn" the labels "exemplary" and "commendable" are made public; rankings are allegedly published to ensure the public that school quality is being objectively measured, including the quality of a school's leaders and teachers. The prized label of "exemplary" is, by policy, only awarded by the state to the top $10 \%$ of high-achieving schools. Therefore, by design, only a small fraction of schools can ever hope to be rated exemplary. But should not all communities have access to exemplary schools which offer exemplary education? Is not this the promise of public education? To cordon off a small fraction of those labeled exemplary, the state thus manufactures the guarantee that $90 \%$ of Illinois' public schools will be less-than-exemplary, and that many will be deemed troubled and failing. Such stratification yields the ratings and fuels the engine of the "bad school industrial complex" (Otto, 
2021), a neoliberal market created for school improvement in a system where many schools fail to meet state norms, always by design.

State-mandated comparison pits schools against one another and fuels competition, but also establishes and maintains a state-imposed hierarchy of implied success in which it is assumed that schools labeled "exemplary" are staffed by educators who somehow are more capable of or superior in teaching. The policy's hierarchical labeling system ensures a permanent flow of "bad schools" in need of saving, creating and perpetually fueling the neoliberal "bad school industrial complex" (Otto, 2021). In this sense the Network enacts professional development as a spectacle of punishment. Similar to the modern-day penal system in which the body is no longer tortured and punished, but rather the soul is imprisoned by omnipresent surveillance and examination (Foucault, 1995), the humiliation enacted on bad school staff and communities through routine public spectacle and those sanctions attached to failing schools imprison failing schools' educators and make it unlikely, if not impossible, a staff can ever turn a school from "failing” to "exemplary." As Foucault teaches us, once a society embraces punishment of the soul as a means to normalize and control its members, there is little way to recover and even fewer chances to thrive since surveillance is omnipresent and all acts are measured in order to enact control and reward docility. In fact, I argue the IL ESSA intentionally enacts the good school/bad school dichotomy to promote educational meritocracy, in effect mandating resilience of failing schools' staff. The IL ESSA places obstacles to be overcome in front of teachers and schools allegedly to transform teacher pedagogy in order to remove the school's failing label. If, even given state resources, school staff cannot do so, they face persistent labeling and sanctioning year after year. 


\section{The Real Power of the IL ESSA}

The IL ESSA sets out to control professional learning for educators, yet does so not in a way that creates dynamic, expert educators, but rather in a way that creates docile educators who teach via state-mandated, rote, mechanized, highly scripted instruction (Anyon, 2011; Finn, 2009). The IL ESSA claims to set out to improve educator effectiveness, but the means by which it enacts professional learning cannot and do not deliver that outcome. What the IL ESSA does effectively is it controls schools' reliance on the state as sovereign warder. Through the IL ESSA the state creates a permanent need for the sovereign because, by design, there will always be failing schools who then rely on the state to be "fixed” or "cured.” The state controls labeling, so controls the humiliation, pervasive negativity, and self-fulfilling prophesy of the good school/bad school dichotomy. The IL ESSA calls for sanctioning schools labeled as troubled and failing to participate in training activities from the IL-EMPOWER Network (until their achievement levels increase sufficiently) but also requires them to pay state-approved Network providers for professional learning consultation and services. The implication that bad schools are incapable of making improvements or seeking their own resources permanently deprofessionalizes and infantilizes failing schools’ staff in addition to imposing the public spectacle of school labeling.

State control is not the control articulated in the policy’s introduction. Rather, it is enacted through the failure of failing schools ever to escape state control. The $90 \%$ of schools in the state labeled less-than-exemplary will always remain under the state's control, under the warder's surveillance (Foucault, 1995). The state will control failing schools' staff's use of time, space, and movement while diminishing already-depleted funds; the state will always argue socalled failing schools will require and receive the paternal hand and eye of the state. 


\section{Recommendations}

In this critical discourse analysis I focus on one policy in one state, but my analysis of IL policy can offer insight into state-mandated educational processes more generally. The highstakes accountability movement in PK-12 education reliably enables and reifies what Tuck (2009) conceptualizes as a damage-centered, one-dimensional approach to defining schools, educators, students, and communities. This pernicious colonial narrative fetishizes those communities characterized as “damaged”: blaming, shaming, and penalizing struggling communities rather than restructuring social systems away from punitive, hierarchical judgment and toward creative, dynamic, strengths-based approaches to school improvement through professional learning. Following the wisdom of Tuck (2009), a damage-centered approach of blaming and shaming must be replaced with a "desire-centered" approach (p. 416). This applies historically to marginalized peoples and research conducted in their communities, but also is applicable to injury inflicted on educators who support underrepresented youth in marginalized, underserved communities in particular. Policies such as the IL ESSA that label schools and educators as failures are focused on damage, not improvement, transformation, or justice. State educational policy should not be built upon damage-centered (Tuck, 2009) brokenness or pit schools against one another within the good school/bad school dichotomy. Rather, a desirecentered approach such as Illinois’ recently passed Culturally Relevant Teaching and Leading Standards (CRTLS) can help reframe the focus on what is most desirable in professional learning, and how that learning translates to serving the community at the local, classroom level. Specifically, Illinois' CRTLS call for educators to embrace an asset-based approach that respects diversity among students, families, and communities, creating teachers and educational leaders who are prepared to serve all students well and justly. The standards recognize such a mindset 
comes only through self-reflection, exploration of backgrounds, in-depth knowledge of a school community's cultures, and critical reflection on the schools and classrooms can and should be established to support all students.

While the IL ESSA does little more than blame underperforming schools, Illinois’ recent CRTLS legislation, sponsored by the Illinois Black Caucus, flips the sorts of surveillance typically used only to blame and punish to the equity side. Illinois’ legislative Black Caucus, a group often marginalized, disciplined, and silenced, as a consequence of policies such as IL ESSA, rose up, empowered to use their outsiderness to flip policy and practice, chose to enact a potential turning point that directly challenges the power and influence of the warder's gaze. The IL Culturally Responsive Teaching and Leading Standards (CRTLS) reveal a state-mandated and maintained system of educational inequities that does not serve Illinois' schools fairly or well; legislators instead call for professional collaboration among educators designed better to understand prejudice, discrimination, and racism, and to radically shift the narrative away from damage, beginning with a new perspective on the norms and targets IL ESSA outlines for all schools. A policy that outlines the same targets for all schools does little to address individual schools' and community's needs, rather centers a damage-centered decision-making approach to school improvement in which marginalized, minoritized, and underrepresented groups are oversurveilled, over-researched, and painted by those evaluators as broken or as failures, even in programs designed to help change their circumstances. The deficit-based labels “at-risk” and “underperforming” are dead ends that perpetuate an educational underclass—an underclass that joins the workforce as a manufactured underclass. Such punitive labels are designed to communicate the social place and economic worth of failing schools’ students, staff, and communities, meant not to transform economically, but to socialize students into those social 
institutions Foucault describes as producing parallel social functions of control and normalization. Most of these types of social institutions, such as factories, prisons, the military, and hospitals, are designed for adults and could be avoided by adults, theoretically, yet schools impose the controlling functions of these social institutions on children who are compelled by law to attend, socializing children into adult social institutions.

The state's management of time, space, and movement in the Gobelin school factory model devalues educators and demotivates them which thwarts the transference of creative professional development into practice (Breneselovic \& Krnjaja, 2012). The IL-EMPOWER Network replaces the state's previous one-source model that required schools to use consulting services from one vendor who bid on and received a contract with the state for professional development. While the IL-EMPOWER Network is a factory model, returning to the model it replaced, of one-source PD offerings is ill advised. The state needs to move forward, and not rely on one-source systems that have political implications from one person or groups of persons with a political or personal interest.

Not only is the factory model ineffective and vulnerable to political influence, it can also tear down the confidence of educators. The IL ESSA's destructive use of teacher labels such as “ineffective” and "inexperienced” also blame, shame and humiliate. The Gobelin school factory approach to professional learning uses labels to divide tasks for those whom are designated by the model as those who fail to be normalized by the disciplinary mechanisms. But failure is not transitory, rather it is made perpetual due to teachers' loss of creativity in classrooms. Teachers are made docile and disengaged in such an industrial structure (Breneselovic \& Krnjaja, 2012). A guild-based model encourages teachers to become curators of their own learning and offers a professional learning approach that provides a deeper level of engagement in critical thinking on 
difficult topics. If, and only if, educators are restored as professionals and treated as adult learners can teachers truly engage in high levels of learning where educators collaborate on innovative and timely topics relevant to improvement (Hargreaves \& Fullan, 2012). Such a change will require the voices of adult learners to be embraced, professional development opportunities to be job-embedded (Breneselovic \& Krnjaja, 2012), and teachers to become more than docile bodies who check off tasks to be completed in Gobelin-like activities that reproduce social inequities and limit social class mobility.

In order to meet Illinois' new Culturally Relevant Teaching and Leading Standards, and in order to serve all children, families, and communities justly and well, the IL ESSA policy must be revised better to address the needs of educators and schools rather than the desires of the state. The fear and intimidation the policy instills in schools that are threatened by sanctions or a label of "failure" encourages submission to the IL-EMPOWER Network but cannot deeply influence educator improvement the way professional collaboration and peer relationships can. “Foucault's explanation infers that our interpersonal relationships, which provide a sense of pleasure and well-being, are stronger determinants of how we experience and enact power than the fear and oppression that might characterize our structured organizational entanglements” (Dixon, 2007, p. 291). This revelation is an important one for the influence of peer relationships on the effectiveness of professional collaboration and learning.

At stake is the continued social inequity that currently ranks the United States at the bottom of the list of social and economic inequity across the globe (Hargreaves \& Fullan, 2012). Discrepancy across social classes in the form of the wealth gap, coupled with the imposition of the myth of meritocracy, fuel policies and measurement systems established as quick and simple solutions (Hargreaves \& Fullan, 2012). However, such policy fails when it labels schools and 
educators, places them in contest with one another, inserts punishments, and requires schools to pay their "better labeled" peers for professional learning consultation. Voluntarily established peer relationships are far more influential than the relationship between a supervisor subordinate or authority in power and an individual (Dixon, 2007). While sanctions imposed by the IL ESSA and the Illinois State Board of Education instill fear, concern, and humiliation in failing schools' staff, sanctions do little to influence the most important aspects of education.

In my role as Superintendent, based on my analysis I recommend locally that schools establish time within the day for peers to collaborate and build their background through professional learning communities. Collaboration and professional learning activities should use the pillars of CRTLS and voices of colleagues from marginalized, minoritized, underrepresented groups. If we are to engage teachers more effectively in creative and thoughtful learning, teachers cannot continue to be seen by the state as passive, compliant learners. Compliance and passivity should never be privileged qualities among excellent teachers. Topics of professional learning should honor backgrounds of students outside of the classrooms (Emdin, 2016) and be opportunity-based, rather than damage-centered (Tuck, 2009). At the state level, challenging the norm and amplifying voices of marginalized youth and educators will require the IL ESSA better to reflect the needs of adult professional learners. If Network providers are exclusively made up of members of the dominating culture from middle-class, "successful” schools, growth opportunities will forever be limited; white, middle-class school staff can no longer be empowered as gatekeepers of failing schools if professional learning is to lift struggling schools. Paradoxically the IL ESSA offers, for, "When a problem of practice emerges from a previous context, it is not a rejection of the past. It is an opportunity to learn from the past by taking parts that were important and placing them in a new context” (ESSA, p. 10). In order appropriately to 
deconstruct prior-held perspectives of the dominating group, teachers must be provided the opportunity to unlearn, to hear from voices of those who come from all backgrounds, and to understand the vital importance of racial, cultural, and economic diversity in the learning process.

Based on my analysis, I recommend revisions to the IL ESSA, if reauthorized or replaced, in order to establish systems to include input from individual teachers in professional development design, especially the perspectives of minoritized educators. A new version of the IL ESSA should be built on a guild-based, systemic model of professional development where educators rely on scientific research and their own practices with collaboration and observation (Breneselovic \& Krnjaja, 2012). Resources of time and funding should be allocated in support of collaboration, mentoring and joint work in scientific and practical research (Breneselovic \& Krnjaja, 2012; Hargreaves \& Fullan, 2012).

When failing to meet norms, a school faces the punitive requirement to enter the ILEMPOWER Network and then must prove worthy before being allowed to exit the Network. This external validation lives through the warder in the system's panopticon, as the warder constantly surveils performance data. Unseen yet pervasive, the agency serves in a position of subtle power and functions like a machine of hierarchized surveillance (Foucault, 1995). Yet, "In high-performing, socially just, and cohesive countries, teachers are not merely dedicated, or even champions. Teachers are complete professionals” (Hargreaves \& Fullan, 2012, p. 185).

Regarding large-scale educational policies and the legislation of professional learning, whether a policy moves social institutions toward true equity depends upon the discourse of the policy versus the implementation of the policy or the metrics used to measure it. In a historical perspective of U.S. education, the manufactured crisis of public education that began in the 
1950s with the race to space, and how that narrative has been used to defund and blame U.S. public schools the stage was set to paint public schools as failures. Surveillance is used to lull the public into losing track of the source of power (Foucault 1982, 1995). The system of power becomes more complex as it is dispersed over organizations, intentionally preventing individuals from surveilling the state itself, thereby evading public critique or recognition. At the same time, it is vital to note that power is not always a bad thing to be critiqued and dismantled. Large-scale U.S. federal policy has legislated important, widespread positive change over the past decades with regard to racial equity. This work could never have been accomplished without the dynamic of the state's expression of power and the laws used to uphold the policies.

My task in this analysis of the IL ESSA may appear to some to be a theoretical exercise, but this policy analysis has significant practical applications. From the perspective of my role as Superintendent of Schools, when I began my dissertation research I was focused on concerns regarding the influence of the IL ESSA policy on the use of resources, time and money, specifically in the area of teachers’ professional learning. I began this project with deep concern about the ways public dollars were wasted and how individual educators' time was being wasted. As I entrenched myself deeper into the literature and policy, I discovered an even more important area of concern about the influence of policies such as the IL ESSA. My time spent reflecting on and analyzing this policy illuminates my concern about the state’s message to educators in "bad schools" and the way the state seeks to make docile bodies out of educators in failing schools. As an educational leader I know students need and deserve teachers who are actively engaged in learning themselves. They deserve teachers who think creatively and use innovation to explore themes of diversity, equity, and inclusion: teachers who eschew colonizing educational practices. This is a viable path to take in order to begin to circulate professional capital and seek social 
justice and prosperity (Hargreaves \& Fullan, 2012) for the nation’s educators, particularly those in troubled and failing schools. 


\section{REFERENCES}

Anyon, J. (2011). Marx and education. New York, NY \& London, UK: Routledge.

Archibald, S., Coggshall, J., Croft, A., \& Goe, L. (2011). High-quality professional development for all teachers: Effectively allocating resources [Research and policy brief]. National Comprehensive Center for Teacher Quality. https://files.eric.ed.gov/fulltext/ED520732.pdf

Attewell, P. A., \& Lavin, D. E. (2009). Passing the torch: Does higher education for the disadvantaged pay off across the generations? New York, NY: Russell Sage Foundation.

Barthes, R. (1978). The death of the author. In Image-music-text (S. Heath, Trans.) (pp. 142148). New York, NY: Hill \& Wang.

Basit, T. (2003). Manual or electronic? The role of coding in qualitative data analysis. Educational Research, 45(2), 143-154.

Bill \& Melinda Gates Foundation. (2014). Teachers know best: Teachers’ views on professional development [in collaboration with Boston Consulting Group]. Bill \& Melinda Gates Foundation. http://k12education.gatesfoundation.org/resource/teachers-know-bestteachers-views-on-professional-development/

Bowles, S., \& Gintis, H. (2011). Schooling in capitalist America: Educational reform and the contradictions of economic life. Chicago, IL: Haymarket Books.

Breneselović, D. P., \& Krnjaja, Z. (2012). School is not a factory-interactive system of professional development: Networking. Journal of Education and Future, 1, 133-142. https://www.researchgate.net/publication/236974808_School_is_not_a_factoryInteractive_System_of_Professional_Development_Networking 
Brooks, J. G., \& Brooks, M. G. (1993). In search of understanding: The case for constructivist classrooms. Alexandria, VA: Association for Supervision and Curriculum Development.

Burke, C. W., \& Kunichoff, Y. (2018, October 30). Illinois report card: 94 Chicago schools earn low performance rating. Chalkbeat. https://www.chalkbeat.org/posts/chicago/2018/10/30/xx-high-schools-earn-lowperformance-rating-on-new-illinois-report-card/

Burr, V. (2015). Social constructionism (3 ${ }^{\text {rd }}$ ed.). New York, NY \& London, UK: Routledge.

Bushnell, M. (2003). Teachers in the schoolhouse panopticon: Complicity and resistance. Education and Urban Society, 35(3), 251-272.

Calvert, L. (2016). Moving from compliance to agency: What teachers need to make professional learning work. Oxford, OH: Learning Forward and NCTAF. https://learningforward.org/wp-content/uploads/2017/08/moving-from-compliance-toagency.pdf

Carter Andrews, D. J., \& Richmond, G. (2019). Professional development for equity: What constitutes powerful professional learning? Journal of Teacher Education, 70(5), 408-409. doi:10.1177/0022487119875098

Chandrasegaran, J., \& Padmakumari, P. (2018). The role of self-fulfilling prophecies in education: Teacher-student perceptions. I-Manager's Journal on Educational Psychology, 12(1), 8-18. https://files.eric.ed.gov/fulltext/EJ1186415.pdf

Choy, S. P., Chen, X., \& Bugarin, R. (2006). Teacher professional development in 1999-2000: What teachers, principals, and district staff report. Washington, DC: National Center for Education Statistics.

Coates, T.-N. (2015). Between the world and me. New York, NY: Random House. 
Daloz. L. A. (1983). Mentors: Teachers who make a difference. Change: The Magazine of Higher Learning, 15(6), 24-27. doi: 10.1080/00091383.1983.10570000

DeMonte, J. (2013, July). High-quality professional development for teachers: Supporting teacher training to improve student learning. American Progress. Washington, DC: Center for American Progress. https://www.americanprogress.org/wpcontent/uploads/2013/07/DeMonteLearning4Teachers-1.pdf

de Tocqueville, A. (1945). Democracy in America (vol. II). New York, NY: Alfred A. Knopf. Danielson, C., \& McGreal, T. L. (2000). Teacher evaluation to enhance professional practice. Alexandria, VA: Association for Supervision and Curriculum Development.

Danielson, C. (2007). Enhancing professional practice: A framework for teaching $\left(2^{\text {nd }}\right.$ ed.). Alexandria, VA: Association for Supervision and Curriculum Development. (Original work published 1996)

Darling-Hammond, L., \& McLaughlin, M. W. (1995). Policies that support professional development in an era of reform. Phi Delta Kappan, 76(8), 597-604. https://www.kappanonline.org/policies-that-support-professional-development-in-an-eraof-reform/

Desimone, L. M., Porter, A. C., Garet, M. S., Yoon, K. S., \& Birman, B. F. (2002). Effects of professional development on teachers' instruction: Results from a three-year longitudinal study. Educational Evaluation and Policy Analysis, 24(2), 81-112.

Destin, M. (2020). The double-edged consequences of beliefs about opportunity and economic mobility. The Future of Children, 30(1), 153-163. https://eric.ed.gov/?id=EJ1262714 
Dixon, M. A. (2007). Transforming power: Expanding the inheritance of Michel Foucault in organizational studies. Management Communication Quarterly, 20(3), 283-296. http://citeseerx.ist.psu.edu/viewdoc/download?doi=10.1.1.848.5185\&rep=rep1\&type=pdf

DuFour, R., \& Eaker, R. (1998). Professional learning communities at work: Best practices for enhancing student achievement. Bloomington, IN: Solution Tree.

DuFour, R., DuFour, R., \& Eaker, R. (2008). Revisiting professional learning communities at work: New insights for improving schools. Bloomington, IN: Solution Tree.

DuFour, R., \& Fullan, M. (2013). Cultures built to last: Systemic PLCs at work. ${ }^{\mathrm{TM}}$ Bloomington, IN: Solution Tree.

DuFour, R. (2014). Harnessing the power of PLCs. Educational Leadership: Professional Learning: Reimagined, 71(8), 30-35.

Emdin, C. (2016). For white folks who teach in the hood...and the rest of y'all too: Reality pedagogy and urban education. Boston, MA: Beacon Press.

Emerson, R. M., Fretz, R. I., \& Shaw, L. L. (2011). Writing ethnographic fieldnotes (2 ${ }^{\text {nd }}$ ed.). Chicago, IL: The University of Chicago Press.

ESSA (2015). Every Student Succeeds Act of 2015, Pub. L. No. 114-95 § 114 Stat. 1177 (2015-2016).

Fallon, G., \& Barnett, J. (2009a). Impacts of school organizational restructuring into a collaborative setting on the nature of emerging forms of collegiality. International Journal of Education Policy \& Leadership 4(9), 1-14. doi:10.22230/ijepl.2009v4n9a159 
Fallon, G., \& Barnett, J. (2009b). When is a learning community just a pseudo community? Towards the development of a notion of an authentic learning community. International Studies in Educational Administration, 37(2), 3-24.

Fairclough, N. (2012). Critical discourse analysis. In P. Gee \& M. Handford (Eds.), The Routledge handbook of discourse analysis. New York, NY \& London, UK: Routledge.

Finn, P. (2009). Literacy with an attitude: Educating working-class children in their own selfinterest ( $2^{\text {nd }}$ ed.). Albany, NY: State University of New York Press.

Foucault, M. (2007). Security, territory, population: Lectures at the Collège de France, 19771978 (G. Burchell, Trans.). London, UK: Palgrave Macmillan.

Foucault, M. (1982). The subject and power. Critical Inquiry, 8(4), 777-795. doi: $10.1086 / 448181$

Foucault, M. (1995). Discipline and punish: The birth of the prison. New York, NY: Vintage.

Frostenson, M. (2015). Three forms of professional autonomy: De-professionalisation of teachers in a new light. Nordic Journal of Studies in Educational Policy, 2(28464), 20-29. doi: 10.3402/nstep.v1.28464

Fullan, M. (1991). The new meaning of educational change. New York, NY: Teachers College Press.

Gee, J. P. (2011). An introduction to discourse analysis: Theory and method. New York, NY: Routledge.

Goodman, L. V. (1976). A nation of learners. Washington, DC: U.S. Government Printing Office.

Hall, S., Evans, J., \& Nixon, S. (Eds.). (2013). Representation. London, UK: SAGE. 
Hilliard, III, A. (1997). The structure of valid staff development. Journal of Staff Development, 18(2), 28-34.

Hargreaves, A., \& Fullan, M. (2012). Professional capital: Transforming teaching in every school. New York, NY: Teachers College Press.

Hord, S. M. (2009). Professional learning communities: Educators work together toward a shared purpose—improved student learning. Journal of Staff Development, 30(1), 40-43.

Hochberg, E., \& Desimone, L. (2010). Professional development in the accountability context: Building capacity to achieve standards. Educational Psychologist, 45(2), 89-106.

hooks, b. (2000). Where we stand: Class matters. New York, NY \& London, UK: Routledge. Illinois State Board of Education. (2019). IL-EMPOWER. Springfield, IL: ISBE. https://www.isbe.net/IL-EMPOWER

Illinois State Board of Education (2018). IL-EMPOWER: The IL quality framework and supporting rubric [Brochure]. Springfield, IL: ISBE.

Jaquith, A., Mindich, D., Wei, R. C., \& Darling-Hammond, L. (2010). Teacher professional learning in the United States: Case studies of state policies and strategies [Technical report]. Oxford, OH: Leaning Forward, \& Stanford, CA: Stanford Center for Opportunity Policy in Education. https://www.learningforward.org/docs/defaultsource/pdf/2010phase3technicalreport.pdf?sfvrsn=0

Knowles, M. (1973). The adult learner: A neglected species. Largo, FL: Gulf.

Lieberman, A. (1995). Practices that support teacher development: Transforming conceptions of professional learning. In Innovating and evaluating science education: NSF evaluation forums 1992-94 (pp. 67-72). Washington, DC: National Science Foundation. 
Little, J. W. (1993). Teachers’ professional development in a climate of educational reform. Educational Evaluation and Policy Analysis, 15(2), 129-151.

Little, J. W. (1990). The persistence of privacy: Autonomy and initiative in teachers’ professional relations. Teachers College Record, 91(4), 509-536.

Love, B. (2019). We want to do more than survive: Abolitionist teaching and the pursuit of educational freedom. Boston, MA: Beacon Press.

Markovits, D. (2020). The meritocracy trap: How America's foundational myth feeds inequality, dismantles the middle class, and devours the elite. New York, NY: Penguin.

McAdamis, S. (2007). A view of the future: Teamwork is daily work. Journal of Staff Development, 28(3), 45-47.

McAdamis, S. (2008). Don’t just participate-engage in learning. National Staff Development Council, 29(1), 9.

McKenzie, K., \& Scheurich, J. (2004). Equity traps: A useful construct for preparing principals to lead schools that are successful with racially diverse students. Educational Administration Quarterly, 40(5), 601-632. https://doi.org/10.1177/0013161X04268839

National Defense Education Act of 1958, P.L. 85-864; 72 Stat. 1580 (1958).

No Child Left Behind Act of 2001, P.L. 107-110, 20 U.S.C. § 6319 (2002).

Noguera, P., \& Syeed, E. (2020). City schools and the American dream 2 : The enduring promise of public education. New York, NY: Teachers College Press.

Norton, J. (2001). Grounded in research. Journal of Staff Development, 22(3), 30-32.

Null, J. W. (2004). Is constructivism traditional? Historical and practical perspectives on a popular advocacy. The Educational Forum, 68, 180-188. 
O’Neil, J. (1995). On schools as learning organizations: A conversation with Peter Senge. Educational Leadership, 52(7), 20-23.

Otto, S. (2021). Bad school industrial complex. http://www.badschoolindustrialcomplex.com/

Penuel, W. R., Fishman, B. J., Yamaguchi, R., \& Gallagher, L. P. (2007). What makes professional development effective? Strategies that foster curriculum implementation. American Educational Research Journal, 44(4), 921-958.

Petrilli, M. J., \& Wright, B. L. (2020). America’s mediocre test scores: Education crisis or poverty crisis? Education Next, 16(1). https://www.educationnext.org/americas-mediocretest-scores-education-poverty-crisis/

Poole, W. L. (2000, Spring). The construction of teachers' paradoxical interests by teacher union leaders. American Educational Research Journal, 37(1), 93-119.

Rhodes, C., \& Beneicke, S. (2002). Coaching, mentoring and peer-networking: Challenges for the management of teacher professional development in schools. Journal of In-Service Education, 28(2), 297-310.

Ricken, J. (2011). The influence of leadership practices and guiding values on professional relationships within professional learning communities [Unpublished doctoral dissertation]. Illinois State University.

Rivera, L. A. (2015). Pedigree: How elite students get elite jobs. Princeton, NJ: Princeton University Press.

Sarason, S. B. (1996). Revisiting "The culture of the school and the problem of change." New York, NY: Teachers College Press. 
Schmoker, M. (2006). Results now: How we can achieve unprecedented improvements in teaching and learning. Alexandria, VA: Association for Supervision and Curriculum Development.

Senge, P. M. (1990). The fifth discipline: The art and practice of the learning organization. New York, NY: Doubleday/Currency.

Shedrow, S. J. (2017). Cross-cultural student teaching: Examining the meaning-making of one white, female, middle-class preservice teacher. Journal of International Students, 7(2), 270-290.

Singleton, G. E. (2015). Courageous conversations about race. Thousand Oaks, CA: Corwin. Sparks, D. (2004). Leading for results: Transforming teaching, learning and relationships in schools ( $2^{\text {nd }}$ ed.). Thousand Oaks, CA: Corwin.

Sparks, D., \& Hirsh, S. (1997). A new vision for staff development. Alexandria, VA: Association for Supervision and Curriculum Development.

Steen, S., \& Noguera, P. A. (2010). A broader and bolder approach to school reform: Expanded partnership roles for school counselors. Professional School Counseling, 14(1), 42-52.

Strong, W. C. (1998). Low expectations by teachers within an academic context. San Diego, CA: American Educational Research Association. (ED420620)

Tauber, R. T. (1998). Good or bad, what teachers expect from students they generally get! Washington, DC: ERIC Clearinghouse on Teaching and Teacher Education. (ED426985)

Taylor, D. C. M., \& Hamdy, H. (2013). Adult learning theories: Implications for learning and teaching in medical education: AMEE guide no. 83. Medical Teacher, 35(11) e1561-72. doi: 10.3109/0142159X.2013.828153 
Tillyard, E. M. (1959). The Elizabethan world picture: A study of the idea of order in the age of Shakespeare, Donne and Milton. New York, NY: Vintage.

Tuck, E. (2009). Suspending damage: A letter to communities. Harvard Educational Review, 79(3), 409-427. doi: 10.17763/haer.79.3.n0016675661t3n15

Urrieta, Jr., L., \& Martínez, S. (2011). Diasporic community knowledge and school absenteeism: Mexican immigrant Pueblo parents’ and grandparents’ postcolonial ways of educating. interventions, 13(2), 256-277.

Urrieta, Jr., L. (2010). Chapter five: Whitestreaming: Why some Latinas/os fear bilingual education. Counterpoints, 371, 47-55.

Valencia, R. R. (2010). Dismantling contemporary deficit thinking: Educational thought and practice. New York, NY \& London, UK: Routledge.

Valli, L., Cooper, D., \& Frankes, L. (1997). Professional development schools and equity: A critical analysis of rhetoric and research. Review of Research in Education, 22(1), 251-304.

van Dijk, T. A. (1993). Principles of Critical Discourse Analysis. Discourse \& Society, 4(2), 249-283. doi: 10.1177/0957926593004002006

van Dijk, T. A. (1995). Aims of critical discourse analysis. Japanese Discourse, 1, 17-27. von Frank, V. (Ed.). (2010). Advancing high-quality professional learning through collective bargaining and state policy: An initial review and recommendations to support student learning. Washington, DC: American Federation of Teachers, Council of Chief State School Officers, National Education Association, \& the National Staff Development Council.

Vygotsky, L. S. (1967). Play and its role in the mental development of the child. Journal of Russian and East European Psychology, 5(3), 6-18. 
Vygotsky, L. S. (1978). Mind in society: The development of higher psychological processes. Cambridge, MA: Harvard University Press.

Wilkerson, I. (2020). Caste: The origins of our discontents. New York, NY: Random House.

Wodak, R., \& Meyer, M. (Eds.). (2016). Methods of critical discourse analysis. London, UK: SAGE.

Yosso, T. J. (2005). Whose culture has capital? A critical race theory discussion of community cultural wealth. Race, Ethnicity and Education, 8(1), 69-91. 